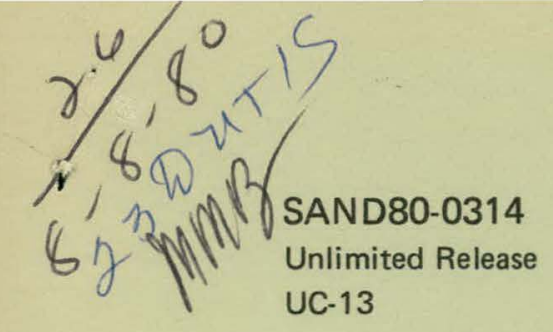

\title{
VASTER
}

\section{Aeroballistic Analysis of ERB/TIGER II Aerodynamic Test Unit ATU-2 (SLA R715032)}

Ronald W. Greene

Prepared by Sandia Laboratories, Albuquerque, New Mexico 87185 and Livermore, California 94550 for the United States Department of Energy under Contract DE-AC04-76DP00789

Printed July 1980

\section{Sandia National Laboratories}




\section{DISCLAIMER}

This report was prepared as an account of work sponsored by an agency of the United States Government. Neither the United States Government nor any agency Thereof, nor any of their employees, makes any warranty, express or implied, or assumes any legal liability or responsibility for the accuracy, completeness, or usefulness of any information, apparatus, product, or process disclosed, or represents that its use would not infringe privately owned rights. Reference herein to any specific commercial product, process, or service by trade name, trademark, manufacturer, or otherwise does not necessarily constitute or imply its endorsement, recommendation, or favoring by the United States Government or any agency thereof. The views and opinions of authors expressed herein do not necessarily state or reflect those of the United States Government or any agency thereof. 


\section{DISCLAIMER}

Portions of this document may be illegible in electronic image products. Images are produced from the best available original document. 
Issued by Sandia National Laboratories, operated for the United States Department of Energy by Sandia Corporation.

NOTICE: This report was prepared as an account of work sponsored by an agency of the United States Government. Neither the United States Government nor any agency thereof, nor any of their employees, nor any of their contractors, subcontractors, or their employees, makes any warranty, express or implied, or assumes any legal liability or responsibility for the accuracy, completeness, or usefulness of any information, apparatus, product, or process disclosed, or represents that its use would not infringe privately by ta re nam. imply its endorsement, recommendation, or favoring by the United States Government any agency thereof or any of their contractors or subcontractors. The views and opinions expressed herein do not necessarily state or reflect those The views and opinions Government, any agency thereof or any of their contractors or subcontractors.

Printed in the United States of America Available from

National Technical Information Service

U. S. Department of Commerce

5285 Port Royal Road

Springfield, VA 22161

NTIS price codes

Printed copy: $\quad \$ 7.00$

Microfiche copy: A01 


\section{PAGES 1 to 2 WERE INTENTIONALLY LEFT BLANK}


SAND80-0314

Unlimited Release

Printed July 1980
Distribution

Category UC-13

\title{
AEROBALLISTIC ANALYSIS OF ERB/TIGER II, AERODYNAMIC TEST UNIT ATU-2 \\ (SLA R7150范)
}

Ronald W. Greene

Aeroballistics Division 5631

Sandia National Laboratories

Albuquerque, NM 87185

\begin{abstract}
The results of the first drop test of the 13.3-indiameter ERB/TIGER II are documented. The test unit, designated Aerodynamic Test Unit-2 (ATU-2), was dropped ui August 25, 1977, at the Sandia National Laboratories Tonopah Test Range from an Air Force F-4 Aircraft. Nominal release conditions were an altitude of $20,000 \mathrm{ft}$ mean sea level and Mach 0.8. The purpose of the test was to obtain free-flight vehicle characteristics including the effect of the free-floating rollerons, to evaluate release and separation characteristics of the 13.3-in-diameter vehicle, and to evaluate the performance of the recovery system. Modifications to the mathematical model for the vehicle that yield better agreement between simulation and flight test results are presented. The system is also described.
\end{abstract}


$\begin{array}{ll}\text { NOMENCLATURE } & 8\end{array}$

Introduction $\quad 11$

ATU-2 Test Objectives $\quad 12$

Description of Test Unit (ATU-2) $\quad 12$

$\begin{array}{ll}\text { Aerodynamic Design } & 12\end{array}$

Trajectory Analysis $\quad 15$

General Description $\quad 15$

Meterological Data 15

Trajectory Data $\quad 15$

$\begin{array}{ll}\text { Rolleron Behavior } & 15\end{array}$

$\begin{array}{ll}\text { Release and Recovery } & 17\end{array}$

F1 ight Dynamic Analysis $\quad 17$

$\begin{array}{ll}\text { Flight Data } & 17\end{array}$

Estrimation of Model Parameters 22

Aerodynamic Model 23

Simulation of Flight Measurements $\quad 24$

$\begin{array}{ll}\text { Parameter Estimation Results } & 26\end{array}$

$\begin{array}{ll}\text { Conclusions } & 42\end{array}$

$\begin{array}{ll}\text { References } & 42\end{array}$

APPENDIX - ATU-2 F1 ight Test Data $\quad 45$ 


\section{ILLUSTRATIONS}

Figure

Page

1 TIGER II Outboard Profile 13

2 Rolleron Description $\quad 14$

3 TIGER II Rolleron/Tail Fin Assembly 17

4 Canard Deflection Sign Convention 20

5 Rolleron Deflection Sign Convention 21

6 Force and Moment Sign Convention 26

7 Comparlson of Measured, and Simulated Altitude 28

8 Comparison of Measured and Simulated X-Axis . 29

9 Comparison of Measured and Simulated Y-Axis 30 Acceleration Histories

10 Comparison of Measured and Simulated Z-Axis Acceleration Histories

11 Comparison of Measured and Simulated Body

Roll Rato Hiotorico

12 Comparison of Measured and Simulated Body

Pitch Rate Histories

13 Comparison of Measured and Simulated Body

Yaw Rate Histories

14 Comparison of Measured and Simulated MARS

Yaw Angle Histories

15 Comparison of Measured and Simulated MARS Pitch Angle Histories

16 Comparison of Measured and Simulated MARS

Roll Angle Histories

17 Angle-of-Attack History Generated by Simulated 
Figure

18 Angle-of-Sideslip History Generated by Simulated Trajectory

19 Aerodynamic Roll Angle History Reconstructed From Lateral Acceleration Measurements
Page

39

40 
Vector of parameters

$C_{l} \quad$ Rolling moment coefficient, $L / \bar{q} s d$

${ }^{c_{\ell}}$

$\partial \mathrm{C}_{\ell} / \partial \delta ;$ Rolleron roll moment effectiveness,

$c_{\ell}$

$\partial \mathrm{C}_{\ell} / \partial(\mathrm{pd} / 2 \mathrm{~V})$ Roll damping due to roll rate,

$\mathrm{C}_{\mathrm{q}}$

$\partial C_{\mathcal{P}} / a(q d / 2 v)$ Roll damping due to pitch rate,

$\mathrm{C}_{\mathrm{l}}$

$\partial C_{\ell} / \partial(r d / 2 v)$ Roll damping due to yaw rate,

$\mathrm{C}_{\mathrm{m}}$

Pitching moment coefficient, $M / \bar{q} s d$

$\mathrm{C}_{\mathrm{m}}$

$\partial C_{m} / \partial \delta$; Rolleron pitching moment effectiveness,

$\mathrm{C}_{\mathrm{m}}$

q

$\partial \mathrm{C}_{\mathrm{m}} / \partial(\mathrm{qd} / 2 \mathrm{~V})$ Pitch damping due to pitch rate,

$\mathrm{C}_{\mathrm{n}}$

Yawing moment coefficient, N/q̄sd

$\mathrm{c}_{\delta}$

$\partial \mathrm{C}_{n} / \partial \delta$; Rolleron yawing moment effectiveness,

$\mathrm{C}_{\mathbf{x}}$

$X$-axis force coefficient, $F_{x} / \bar{q} s$

$c_{y}$

$Y$-axis force coefficient, $F_{y} / \bar{q} s$

$\bar{c}_{\delta}$

$\theta \tau_{y} / \partial \delta ;$ Rolleron force effectiveness,

$\mathrm{C}_{\mathbf{y}}$

$\partial C_{y} / \partial(r d / 2 V)$

$\mathrm{C}_{\mathbf{z}}$

Z-axis force coefficient, $F_{z} / \bar{q} s$

$\mathrm{C}_{\delta}$

$\partial C_{z} / \partial \delta ;$ Rolleron force effectiveness, 


\section{NOMENCLATURE (cont)}

\begin{tabular}{|c|c|}
\hline & $\partial \mathrm{C}_{z} / \partial(\mathrm{qd} / 2 \mathrm{~V})$ \\
\hline $\mathrm{c}_{\mathrm{n}}$ & $\partial C_{n} / \partial(r d / 2 v)$ Yaw damping due to yaw rate, \\
\hline d & Reference length, body diameter ( $f t)$ \\
\hline$F_{x}, F_{y}, F_{z}$ & Aerodynamic forces in $X, Y, Z$ body axes ( $1 b$ ) \\
\hline G & Least-squares performance index \\
\hline $\mathrm{h}$ & Vector of point constraints \\
\hline $\mathrm{K}_{\mathrm{a}}, \mathrm{K}_{\mathrm{h}}$ & Scalar weighting constants \\
\hline$L, M, N$ & Aerodynamic moments in $X, Y, Z$ body axes $(1 b-f t)$ \\
\hline$\ell$ & Dimension of vector of point constraints \\
\hline$M_{n}$ & Mach number \\
\hline $\mathbf{m}$ & Dimension of measurement vector \\
\hline$p, q, r$ & Body angular rates in $X, Y, Z$ body axes ( $\mathrm{rad} / \mathrm{s}$ ) \\
\hline$p^{\prime}$ & Dimension of parameter vector \\
\hline$q^{\prime}$ & Dimension of control vector \\
\hline$q$ & Dynamic pressure $1 / 2 \mathrm{v}^{2} \mathrm{~S}$ \\
\hline S & Reference area, $\pi \mathrm{d}^{2} / 4\left(\mathrm{ft}{ }^{2}\right)$ \\
\hline$t$ & Time (s) \\
\hline
\end{tabular}


NOMENCLATURE (cont)

\begin{tabular}{|c|c|}
\hline $\mathrm{u}$ & Control vector \\
\hline V & Total airspeed $(\mathrm{ft} / \mathrm{s})$ \\
\hline$W_{a}, W_{h}, W_{I}$ & Weighting matrices \\
\hline $\mathbf{x}$ & State vector \\
\hline $\mathbf{y}$ & Simulated measurement vector \\
\hline $\mathbf{z}$ & Actual measurement vector \\
\hline$X, Y, z$ & Body axes \\
\hline$a$ & Pitch-plane angle-of-attack (rad) \\
\hline$\beta$ & Yaw-plane angle-of-attack (rad) \\
\hline$\delta_{i}$ & Deflection of $i$-th rolleron $(i=1,2,3,4)$ ( $r a d)$ \\
\hline$\delta_{y}$ & Pitch canard deflection (rad) \\
\hline$\delta_{z}$ & Yaw canard deflection (rad) \\
\hline$\eta$ & Measurement noise \\
\hline$\theta_{\mathrm{E}}$ & Euler pitch angle (rad) \\
\hline$\theta_{\text {MARS }}$ & MARSS platform pitch gimbal angle (rad) \\
\hline$\xi$ & Total angle-of-attack (rad) \\
\hline$\rho$ & Atmospheric density $\left(\mathrm{slug} / \mathrm{ft}^{3}\right)$ \\
\hline$\phi_{\mathrm{A}}$ & Aerodynamic roll angle (rad) \\
\hline$\phi_{\mathrm{E}}$ & Euler roll angle (rad) \\
\hline$\phi_{\text {MARS }}$ & MARS plat form roll angle ( $\mathrm{rad}$ ) \\
\hline$\psi \mathrm{E}$ & Euler yaw angle (rad) \\
\hline$\psi_{\text {MARS }}$ & MARS platform yaw angle ( $\mathrm{rad}$ ) \\
\hline
\end{tabular}


AEROBALLISTIC ANALYSIS OF ERB/TIGER II

AERODYNAMIC TEST UNIT ATU-2 (SLA R715032)

\author{
Introduction
}

The Tactical Inertially-Guided Extended Range Bomb (TIGER) program, also referred to as Extended Range Bomb (ERB) and Return-To-Target Bomb (RTTB), is an exploratory development program designed to demonstrate the feasibility of improving the performance and deliverability of an existing bomb by the addition of an inertial guidance and control module and a solid propellant rocket motor for added range and maneuverability.

The program has been structured around two similar vehicles that differ primarily in body diameter. The first three flight tests (aerodynamic test unit 1 (ATU-1 $)^{1-3}$ and flight test units 1 and 2 (FTU-1, FTU24) were conducted with the 16.5-in. vehicle. This report documents the first flight test of the 13.3-in-diameter aerodynamic test unit (ATU-2).

The return-to-target flight of FTU-2 exhibited substantial rolling and pitching motion; ${ }^{5}$ it was suggested ${ }^{6}$ that this was due to the variation with aerodynamic roll angle of the aerodynamic characteristics upon which the autopilot had been designed and to the destabilizing effects of floating rollerons. Consequently, the first flight of the 13.3-in. TIGER II vehicle (ATU-2) was designed to assess the effect of rollerons and the validity of the wind tunnel aerodynamic data. Vehicle control was performed open loop (without autopilot stabilization) by step canard deflections selected to yield first a positive angle-of-attack, $a$, and angle$n f-s i d e s l i p, \beta$, followed by a negative $a$ and $\beta$. Rollerons in the $x-z$ body plane were fixed at zero deflection while those in the $x-y$ plane were free to move. It was anticipated that differences in pitch and yaw stability caused by the rollerons would be shown by differing trim angles in the two planes. 
The data obtained from ATU-2 were analyzed to develop modifications to the vehicle mathematical model to more accurately reproduce the actual vehicle flight characteristics. The results of these analyses form the major portion of this report. The remainder of the report is composed of system description.

\section{ATU-2 Test Objectives}

This test was the first drop test of the 13.3-in-diameter TIGER II vehicle. The objectives of the test were to

- Obtain free-flight aerodynamic characteristics including the effert of free-floating rollexum.

- Evaluate release and separation characteristics of the 13.3-in-diameter vehicle.

- Evaluate the performance of the recovery system.

$$
\text { Description of Test Unit (ATU-2) }
$$

\section{Aerodynamic Design}

The TIGER II external shape (Figure 1) conoists of a splere=cone nose section equipped with two pairs of canards for pitch and yaw control, a cyclindrical center section, and a truncated-ogive afterbody equipped with four tail surfaces. The tail surfaces or fins were designed to be stowed during carriage and to be deployed after release, but were fixed in their open position for the f1ight test. A partial 1ist of TIGER physical characteristics 7 is given below. A discussion of the ERB/TIGER II design is contained in Reference 8 .

$\begin{array}{lc}\text { Vehicle length } & 157.3 \mathrm{in} . \\ \text { Reference diameter } & 13.3 \mathrm{in} . \\ \text { Weight } & 847.8 \mathrm{lb} \\ \text { Center of mass } & 70.37 \mathrm{in},\end{array}$


Pitch moment of inertia

Yaw moment of inertia

Roll moment of inertia
297.97 slug-ft 2

$297.97 \mathrm{slug}-\mathrm{ft}^{2}$

5.2881 slug-ft 2

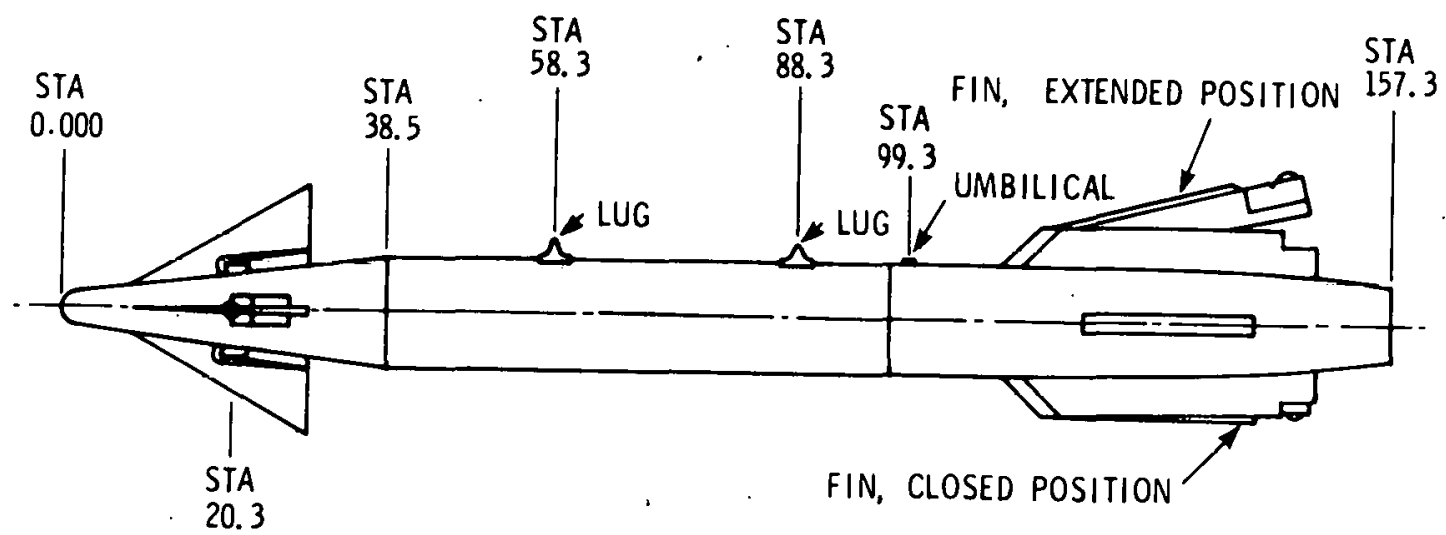

NOTE: LUGS AND UMBILICAL ARE ROTATED $45^{\circ}$ ABOUT LONGITUDINAL AXIS FOR CLARITY

Figure 1. TIGER II Outboard Profile

The TIGER II digital control system computes inertial acceleration commands and then resolves these into the canard axes for implementation. Control system computation rate and actuator requirements are directly related to the maximum roll rate to be encountered during flight. Therefore, it was necessary to maintain the roll rate at a level compatible with. the nominal control system capabiliries.

Cruciform vehicles, especially those that are canard-controlled, exhibit particularly nonlinear roll behavior which is caused by the variability of the flow over the aft surfaces due to body attitude and forward surface deflections. The complexity of the roll moment induced by attitude and control deflection precluded a roll control system based on 
differential canard deflections. Therefore, rollerons 9 of the type used on the AIM-9 Sidewinder air-to-air missile series were selected to maintain acceptable roll rates by providing additional roll damping while avoiding the additional complexity of controllable roll control surfaces and associated actuators.

The rollerons (Figure 2) are small, movable aerodynamic surfaces mounced at the tips of the tail fins. A vaned wheel is partially enclosed within the rolleron in such a way that the relative wind will cause it to spin with its spin axis perpendicular to the rolleron surface. Vehicle roll rate causes precessional torque to be developed about the rolleron hinge line, and the resultant rolleron deflection relative to the tail fin is in the direction to provide an aerodynamic moment to resist roll rate. Added pitch and yaw damping are also obtained because the swept-back hinge line allows pitch and yaw rate components to generate additional precessional torques.

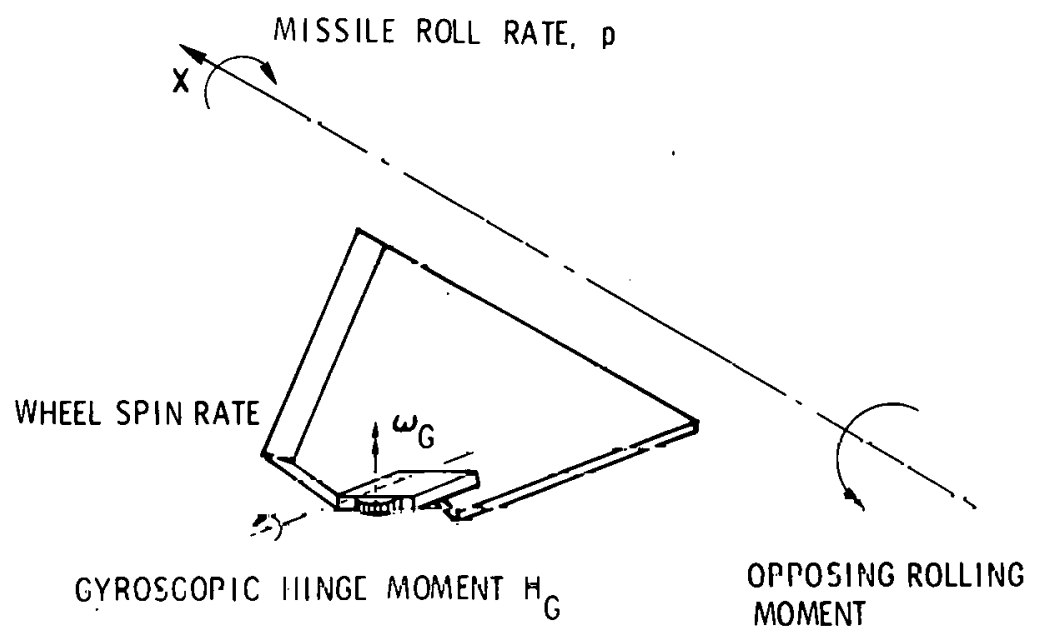

Figure 2. Kolleron Description 
Trajectory Analysis

\section{General Description}

The ATU-2 trajectory was determined from film records obtained from four Contraves cinetheodolite tracking stations. 10

The vehicle was allowed to fall for $8 \mathrm{~s}$ after release before the programmed canard deflection sequence was started. Approximately $20 \mathrm{~s}$ of data were obtained during the canard sequence; payload separation occurred $30 \mathrm{~s}$ after release. Flight test data are presented in the appendix.

\section{Meteorological Data}

Atmospheric data were obtained by means of a radiosonde balloon that was released in the general test area at $1703 \mathrm{hr}$ PDT. The measured atmospheric density (Figure A-1), speed-of-sound (Figure A-2), and winds (Figure A-3 and A-4) were used 10 to compute dynamic pressure and Mach number from Contraves cinetheodolite estimates of altitude and velocity. The atmospheric wind data have been rotated so that the $x$-component coincides with the flight path heading at launch and $y$ is positive to the right. The atmospheric density and speed-of-sound for the standard atmospheric model that was used in the TIGER II systems development simulations are shown in Figures A-5 and A-6 for comparison.

\section{Trajectory Data}

The optically reduced trajectory datal0 are presented in Figures A-7 through A-10. The dynamic pressure, velocity, and Mach number include the effects of speed-of-sound, density, and wind variation with altitude as measured via the radiosonde balloon. These data were used in combination with the telemctry flight test datall to perform the aerodynamic analyses contained in this report.

\section{Rolleron Behavior}

The determination of the effect of rollerons upon the overall aerodynamic stability of the vehicle was one of the objectives of this test. The initial wind tunnel tests $12 ; 13$ were performed with a model 
precluded direct evaluation of the effects of rolleron deflection upon vehicle aerodynamics. Furthermore, examination of rolleron hinge moment characteristics from AIM-9 sidewinder missile aerodynamics ${ }^{9}$ indicated that in the absence of body angular rates the rollerons would trim at deflections approximately one-half the vehicle angle-of-attack. For example, an AIM-9 angle-of-attack of $10^{\circ}$ (nose up) would cause the horizontal axis rollerons to trim trailing-edge up at $\sim 5^{\circ}$. This would produce a decrease in nose down pitching moment and a corresponding decrease in static stability. Estimates of this reduction in stability were initially obtained during the consideration of the 16.5-in. vehicle by removing the rolleron surface area from the tail and performing tests ${ }^{14}$ in the SLA Trisonic Wind Tunnel (TWT). Additional wind tunnel tests ${ }^{15}$ were also run in the CALSPAN transonic facility for the 13.3-in. vehicle in which the simulated rolleron surfaces were allowed to float freely about their hinge lines. The simulated rollerons were fabricated to approximate the actual surfaces in area and did not contain movable wheels; no gyroscopic effects were measured. During this test the rollerons were observed to float to significantly higher angles than had been suggested by the AIM- 9 hinge moment data.

The higher rolleron trim angles are caused by the placement of the rollerons so that the hinge line is nearer the tail leading edge (Figure 3) for the ERB/TIGER II than for the AIM-9.9 In fact, the rulleron forms the leading edge of the tail fin tip. The increased suction near the leading edge of the swept tail surface causes a larger hinge moment and increases the floating tendency. Analysis of the CALSPAN data (digital and film) revealed that the rollerons floated to approximately threc times the test angle-of-attack. 16

Since the nominal return-to-target maneuver requires approximately a $10^{\circ}$ angle-of-attack, the canard deflections were programmed for this flight to produce accelerations and angles-of-attack of $2 \mathrm{~g}$ and $10^{\circ}$, respectively. Therefore, large rolleron deflection angles were expected to vecur. 
The vehicle was released from an F-4 aircraft, and the separation was accomplished as expected. The recovery system performed as expected, and the vehicle forebody was recovered successfully.

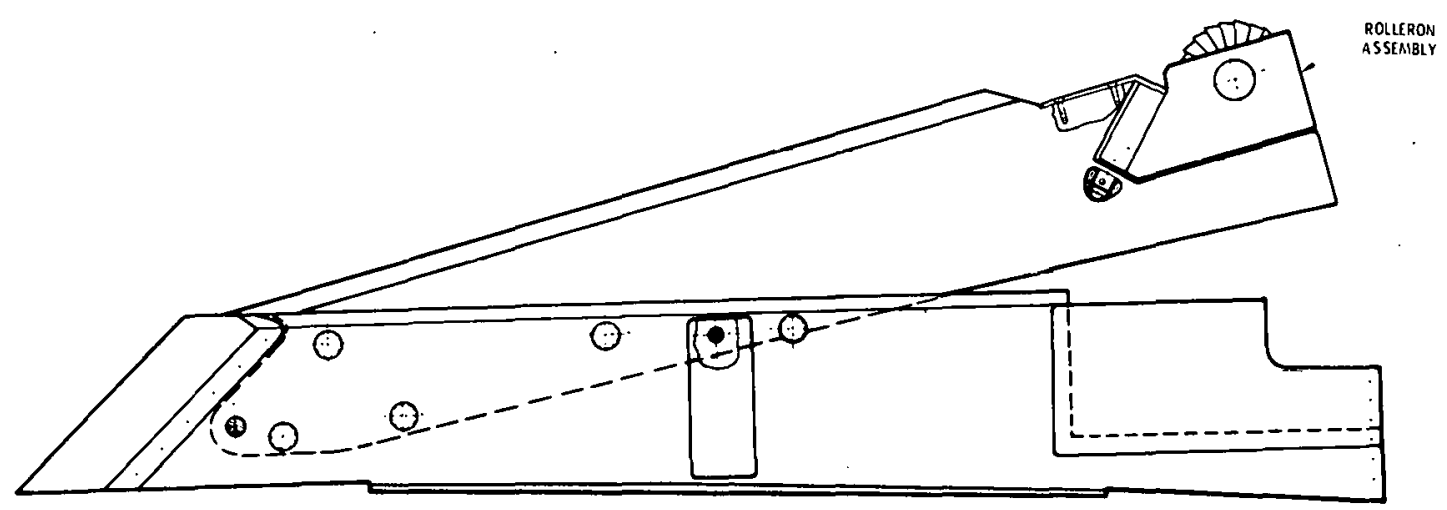

Figure 3. TIGER II Rolleron/Tail Fin Assembly

Flight Dynamic Analysis

\section{Flight Data}

The test unit was equipped with a telemetry system which provided sufficient information ${ }^{2}$ to describe the vehicle motion. The observed quantities 11 that were used in this analysis, along with accompanying accuracy estimaces and variable rangco, are shown in Table 1. A more complete list of available telemetered quantities is included in Reference 17.

The measured canard positions are shown in Figures $A-11$ and $A-12$. The canard deflection sign convention is presented in Figure 4. These histories were pleced together by using the coarse measurements for the first $8 \mathrm{~s}$ and fine measurements for the remainder of the flight in order to realize the best data resolution. The "weathervaning" or floating of the canards during the first $8 \mathrm{~s}$ is apparent. The first $28 \mathrm{~s}$ of data were used in this analyeis. 
Axial and lateral accelerations ( $a_{x}, a_{y}$, and $a_{z}$ ) are presented in Figures $A-13, A-14$, and $A-15$, respectively. The lateral accelerations were adjusted during data reduction to produce an average of $0.707 \mathrm{~g}$ in each axis for 2 s before release to reduce the effects of temperatureinduced bias shifts.18

Vehicle angular rates, $p, q$, and $r$, are shown in Figures $A-16, A-17$, and $A-18$, respectively. The yow rate exhibits a slightly higher frequem than the pitch rate during the first $8 \mathrm{~s}$. If all of this difference is due to the free rollerons, the ratio of static margins is given by

$$
\frac{\mathrm{c}_{a_{\text {free }}}}{\mathrm{c}_{\mathrm{m}_{\text {fixed }}}} \cong\left(\frac{8 / 8}{9 / 7.5}\right)^{2}=0.69 .
$$

This agrees well with the wind tunnel results obtained with rollerons removed. 14

Vehicle attitude angles, (yaw, $\Psi$; pitch, $\theta$ ) and roll, $\phi$, are presented in figures $A-19, A-20$, and $A-21$, respectively. These angloo wcre measured by using a Minature Attitude Reference System (MARs) platform. This roll-stabilized platform was uncaged at release, and the angles measured are therefore referenced to this orientation. Since the vehicle is carried in the $x$-configuration, this coincides with a $45^{\circ}$ roll angle. Simulations performed to compare trajectory predictions were begun with $\phi=45^{\circ}$. Comparisons were perfomed by substracting $45^{\circ}$ frum the simulation roll angle. 
Table 1

ATU-2 Onboard Instrumentation for Vehicle Dynamics

\begin{tabular}{|c|c|c|c|}
\hline Measurement & Samples/s & Accuracy & Range \\
\hline MARS roll & cont & $2^{\circ}$ & $360^{\circ}$ \\
\hline MARS pitch & cont & $10^{\circ}$ & $360^{\circ}$ \\
\hline MARS yaw & cont & $1^{\circ}$ & $\pm 86^{\circ}$ \\
\hline $\begin{array}{l}\text { Roll rate } \\
\text { (coarse) } \\
\text { (fine) }\end{array}$ & $\begin{array}{r}20 \\
\text { cont }\end{array}$ & $\begin{array}{r}16 \% / \mathrm{s} \\
8 \% / \mathrm{s}\end{array}$ & $\begin{array}{l}+400 \% / \mathrm{s} \\
\pm 200 \%\end{array}$ \\
\hline $\begin{array}{l}\text { Pitch rate } \\
\text { (coarse) } \\
\text { (fine) }\end{array}$ & $\begin{array}{r}20 \\
\text { cont }\end{array}$ & $\begin{array}{l}8 \% / 8 \\
4 \% / s\end{array}$ & $\begin{array}{l}+200 \% / \mathrm{s} \\
\pm 100 \% / \mathrm{s}\end{array}$ \\
\hline $\begin{array}{l}\text { Yaw rate } \\
\text { (coarse) } \\
\text { (fine) }\end{array}$ & $\begin{array}{r}20 \\
\text { cont }\end{array}$ & $\begin{array}{l}8 \% / s \\
4 \% / 8\end{array}$ & $\begin{array}{l}+200 \% / \mathrm{s} \\
\pm 100 \% \%\end{array}$ \\
\hline Axial acceleration ( $x$-axis) & 40 & $0: 4 \mathrm{~g}$ & $\pm 5 g$ \\
\hline Lateral acceleration ( $y$-axis) & 40 & $0.4 \mathrm{~g}$ & $\pm 5 g$ \\
\hline Lateral acceleration (z-axis) & 40 & $0.4 \mathrm{~g}$ & $\pm 5 g$ \\
\hline $\begin{array}{l}\text { Y-canard position } \\
\text { (coarse) } \\
\text { (fine) }\end{array}$ & $\begin{array}{l}20 \\
20\end{array}$ & $\begin{array}{l}0.5^{\circ} \\
0.1^{\circ}\end{array}$ & $\begin{array}{l} \pm 15^{\circ} \\
\pm 5^{\circ}\end{array}$ \\
\hline $\begin{array}{l}\text { Z-canard position } \\
\text { (coarse) } \\
\quad \text { (fine) }\end{array}$ & $\begin{array}{l}20 \\
20\end{array}$ & $\begin{array}{l}0.5^{\circ} \\
0.1^{\circ}\end{array}$ & $\begin{array}{l} \pm 15^{\circ} \\
\pm 5^{\circ}\end{array}$ \\
\hline $\begin{array}{l}\text { Rolleron position } 2 \\
\text { (coarse) } \\
\text { (fine) }\end{array}$ & $\begin{array}{l}20 \\
20\end{array}$ & $\begin{array}{l}0.6^{\circ} \\
0.4^{\circ}\end{array}$ & $\begin{array}{l}+30^{\circ} \\
\pm 10^{\circ}\end{array}$ \\
\hline $\begin{array}{l}\text { Rolleron position } 4 \\
\text { (coarse) } \\
\text { (fine) }\end{array}$ & $\begin{array}{l}20 \\
20\end{array}$ & $\begin{array}{l}0.6^{\circ} \\
0.4^{\circ}\end{array}$ & $\begin{array}{l}+30^{\circ} \\
\pm 10^{\circ}\end{array}$ \\
\hline
\end{tabular}




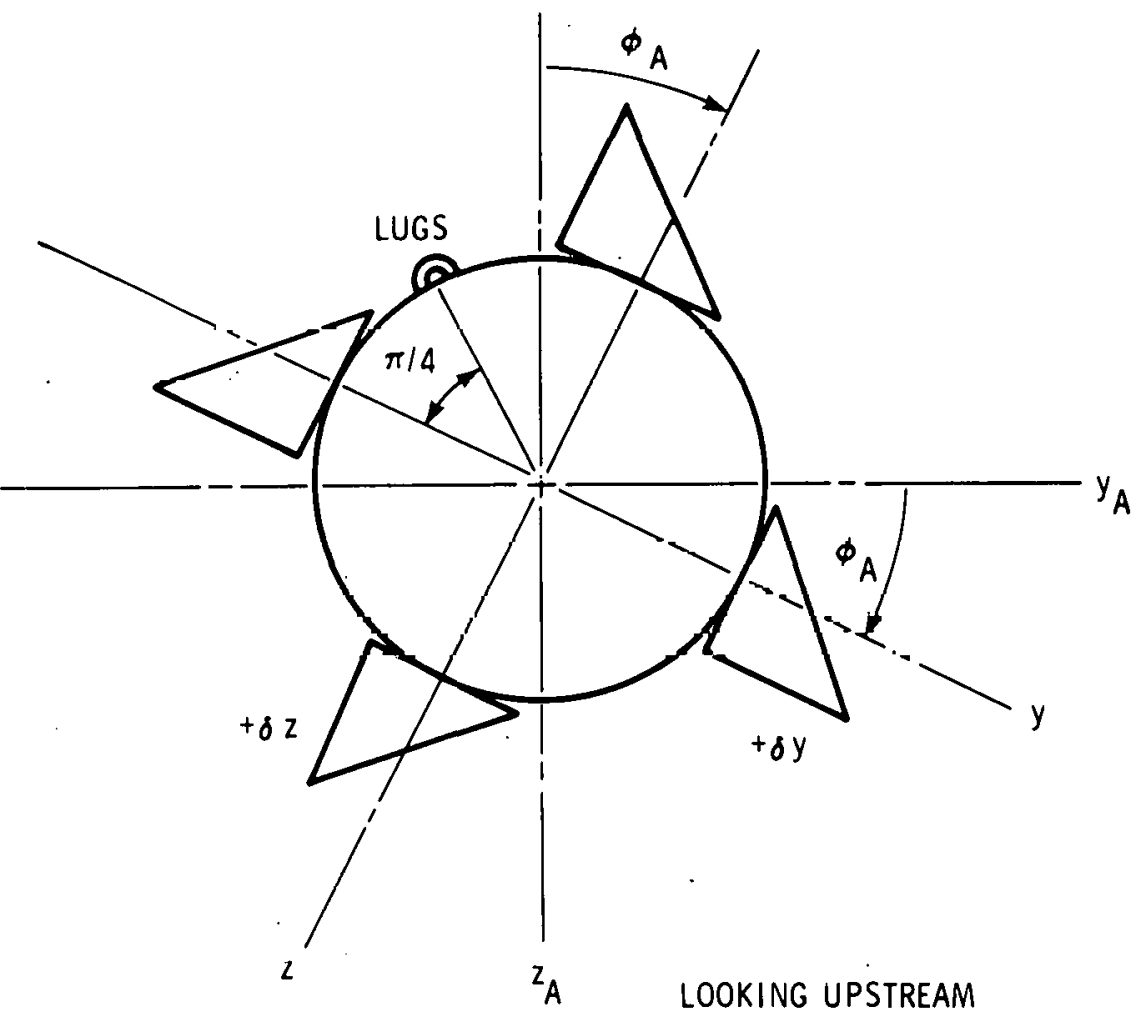

Figure 4. Canard Deflection Sign Convention

Rolleron deflection time histories are shown in Figures A-22 and A23. The rolleron deflections tend to follow the z-acceleration (Figure A15), as expected, because of the dependence of acceleration on angle-ofattack. The positive sign convention (Figure 5) for rollerons 2 and 4 is trailing edge down and up, respectively. The amount of differential deflection is obtained by adding the two deflections and during the two periods of nearly constant deflection is approximately

$$
\begin{array}{ll}
1 \circ & 10<t<18 \mathrm{~s} \\
5^{\circ} & 22<\mathrm{t}<30 \mathrm{~s} .
\end{array}
$$

This behavior was not expected because comparison of the roll rate direction and magnitude during these time periods reveals that 19 
- The differential deflection during the first period is neither significant nor sufficient to reduce the roll rate

- During the second period the deflection is in the wrong direction and is apparently in response to smaller roll rate than in the first period.

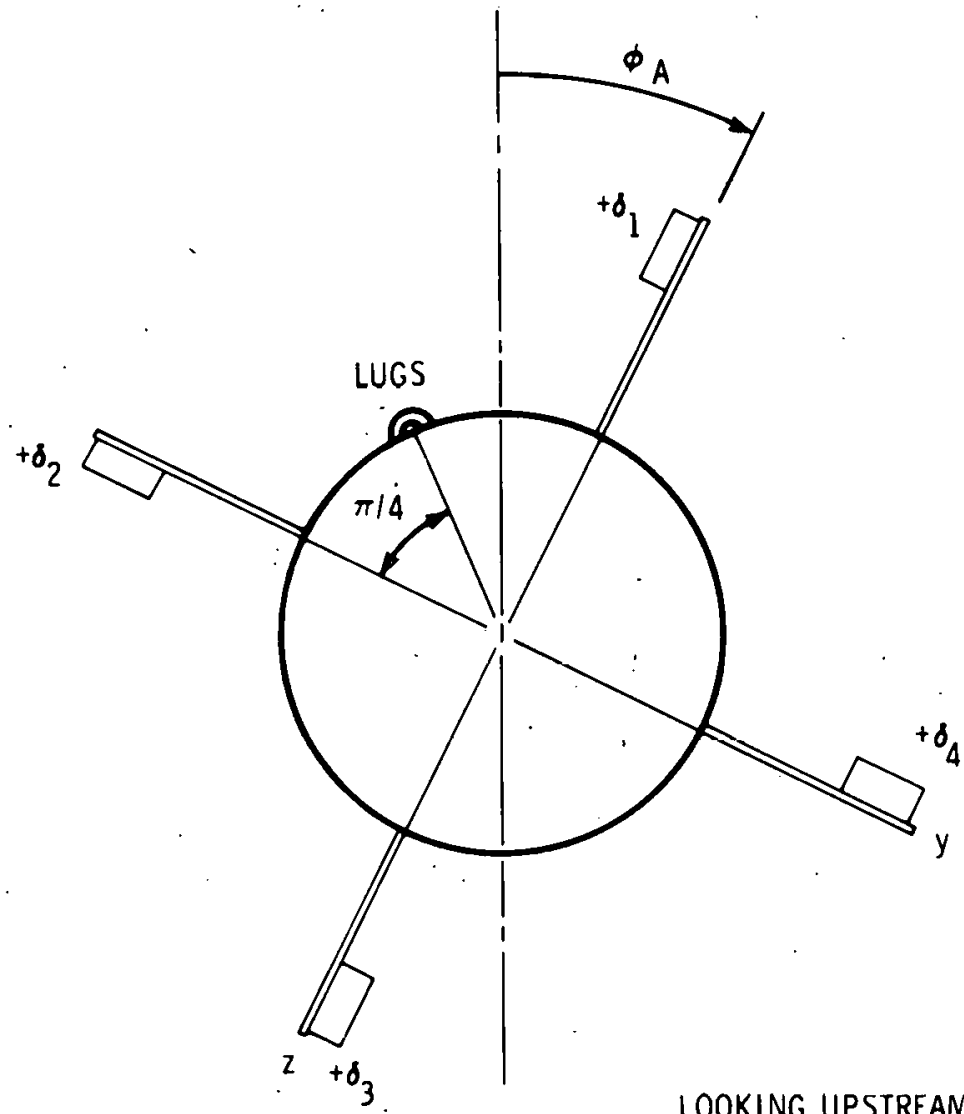

Figure 5. Rolleron Deflection Șign Convention

Subsequent analysis ${ }^{20}$ of rolleron behavior on ATU-2, FTU-3, and FTU-4 flight tests revealed that this unexpected motion can be attributed to the rollerons' tendency to respond strongly to local angle-of-attack. The local angle-of-attack is a complex function of body angle-of-attack, aerodynamic roll angle, and ranard position; it can vary significantly for opposing elements of a rolleron pair. Therefore, for this flight the rollerons were responding more to local angle-of-attack than to roll rate. 


\section{Estimation of Model Parameters}

A six-degree-of-freedom model for the TIGER II vehicle was parameterized in terms of initial vehicle state conditions; aerodynamic coefficients, inertial properties, center-of-mass location, and measurement biases and scale factors. Combinations of these parameters were estimated by using a nonlinear weighted-least-squares method based on the Square Root Variable Metric (SRVM) function minimization algorithm developed by Williamson.21 The parameter vector was chosen to minimize the cost function composed of the weighted sum of the squares of the residuals that existed between observed and simulated measurements. The cost function also included quadratic forms composed of point constraints and of deviations of the parameters from nominal values. The degree of sgreement in a particular measurement was adjusted by modifying the weighting factor associated with that component of the cost function. Nominal weighting factors were chosen based on the accuracy estimates listed in the TM data list 17 (Table 1). The mathematical formulation of the cost function, $G$, is given below.

$$
\begin{aligned}
G & =\left(\frac{1}{t_{f}-t_{0}}\right) \int_{t_{0}}^{t_{f}}\left\{[z(t)-y(t)]^{T} W_{I}[z(t)-y(t)]\right\} d \cdot t \\
& +K_{a}\left(a-a_{0}\right) T_{W_{a}}\left(a-a_{\Omega}\right)+K_{h}\left(h-h_{c}\right) T_{W_{h}}\left(h-h_{c}\right) .
\end{aligned}
$$

\section{Description}

$\dot{x}(t)=f(x, u, a, t)$

$y(t)=g(x, u, t)$

$z(t)=y(t)+\eta(t)$

$h=h(x, u, a, t)$

a

\section{Dimension}

n - dimensional state vector

m - dimensional vector of simulated observation

m - dimensional observation vector

$\ell=$ dimenoional vecton of point constrainls

$p$ - dimensional vector of parameters to be estimated 
$\eta$

$\mathbf{u}$

$\mathbf{w}_{\mathbf{a}}$

WI

$\mathrm{W}_{\mathrm{h}}$

$\mathrm{K}_{\mathbf{a}}, \mathrm{K}_{\mathbf{h}}$ m - dimensionsl vector of measurement noise

$q$ - dimensional control vector

pxp - diagonal matrix of weighting coefficients mxm - diagonal matrix of weighting coefficients

$\ell \times \ell-$ diagonal matrix of weighting coefficients scalar constants

Aerodynamic Model

The nominal aerodynamic model for the systems development simulation of the TIGER II vehicle was based on wind tunnel data that had been obtained with fixed rollerons.12-13 These data were placed in tabular form and interpolated as a function of total angle-of-attack, $\xi$; aerodynamic roll angle, $\phi_{A}$; Mach number, $M_{n}$; and canard deflections, $\delta_{y}$. and $\delta_{z} \cdot$

The aerodynamic force and moment models (Figure 6) for the parameter estimation were based on this tabular model with additional coefficients added to account for the effects of the rollerons and dynamic coupling. The relationships expressing these models are given below:

$$
\begin{aligned}
& C_{x}=c_{x_{\text {Table }}}\left(\xi, M_{n}, \phi_{A}, \delta_{y}, \delta_{z}\right)+c_{x_{B i a s}} \\
& C_{y}=c_{y_{T a b l e}}\left(\xi, M_{n}, \phi_{A}, \delta_{y}, \delta_{z}\right)+c_{y_{B i a s}}+c_{y_{\delta}}\left(\delta_{1}-\delta_{3}\right)+c_{y_{r}} \frac{r d}{2 V} \\
& C_{z}=C_{z_{\text {Table }}}\left(\xi, M_{n}, \phi_{A}, \delta_{y}, \delta_{z}\right)+C_{z_{B i a s}}+C_{z}\left(\delta_{4}-\delta_{2}\right)+C_{z} \frac{q d}{2 V}
\end{aligned}
$$




$$
\begin{aligned}
& c_{\ell}=C_{\ell_{\text {Table }}}\left(\xi, M_{n}, \phi_{A}, \delta_{y}, \delta_{z}\right)+C_{\ell_{B i a s}}+C_{\ell}\left(\delta_{1}+\delta_{2}+\delta_{3}+\delta_{4}\right) \\
& +c_{\ell} \frac{p d}{2 V}+c_{\ell_{q}} \frac{q d}{2 V}+c_{\ell_{r}} \frac{r d}{2 V} \\
& c_{m}=c_{m_{T a b l e}}\left(\xi, M_{n}, \phi_{A}, \delta_{y}, \delta_{z}\right)+c_{m_{B i a s}}+c_{m_{q}} \frac{q d}{2 v}+c_{m_{\delta}}\left(\delta_{4}-\delta_{2}\right) \\
& C_{n}=c_{n_{T a b 1 e}}\left(\xi, M_{n}, \phi_{A}, \delta_{y}, \delta_{z}\right)+c_{n_{K i} \text { S }}+c_{n_{r}} \frac{r d}{2 V}+c_{n_{\delta}}\left(\delta_{3}-\delta_{1}\right)
\end{aligned}
$$

A characteristic of data fitting techniques is that they compensate for unmodeled behavior by adjusting the available parameters. Therefore, errors in the basic aerodynamic model will affect the estimates of the effects of the rollerons. Thus, care must be exercised in using estimates for parameters when the basic trajectory is significantly different (e.g., higher Mach number, different angle-of-attack range, etc).

\section{Simulation of F1ight Measurements}

The accelerations were measured by accelerometers that were not located at the vehicle center-of-mass. Therefore, the simulated accelerations of the center-of-mass were corrected for position to generate simulated accelerometer measurements by using the following:

$$
\overline{\mathrm{a}}_{\mathrm{p}}=\overline{\mathrm{a}}_{\mathrm{cm}}+\bar{\omega} \times\left(\bar{\omega} \times \overline{\mathrm{r}}_{\mathrm{p} / \mathrm{cm}}\right)+\dot{\bar{\omega}} \times \overline{\mathrm{r}}_{\mathrm{p} / \mathrm{cm}}
$$


or in scalar form

$$
\begin{aligned}
& a_{p_{x}}=a_{c m_{x}}-\Delta x\left(q^{2}+r\right)^{2}+\Delta y(p q-\dot{r})+\Delta z(p r+\dot{q}) \\
& a_{p_{y}}=a_{c m_{y}}+\Delta x(p q+\dot{r})-\Delta y\left(p^{2}+r^{2}\right)+\Delta z(q r-\dot{p}) \\
& a_{p_{z}}=a_{c m_{z}}+\Delta x(p r-\dot{q})+\Delta y(q r+\dot{p})-\Delta z\left(p^{2}+q^{2}\right)
\end{aligned}
$$

where

$$
\begin{aligned}
& \Delta x=x_{p}-x_{c m} \\
& \Delta y=y_{p}-y_{c m} \\
& \Delta z=z_{p}-z_{c m} .
\end{aligned}
$$

In addition, the MARS platform gimbal arrangement does not allow direct measurement of both yaw and pitch Euler angles. For the platform orientation used on ATU-2 the relationships between MARS angles and body Euler angles are as follows: 22

$$
\begin{aligned}
& \psi \text { MARS }=\psi_{E} \\
& \text { OMARS }=\tan ^{-1}\left(\tan \cdot\left(\theta_{E}\right) / \cos \left(\psi_{E}\right)\right. \\
& \phi_{\text {MARS }}=\phi_{E}
\end{aligned}
$$

where the Euler rotation sequence is (yaw, $\psi_{E} ;$ pitch, $\dot{\theta}_{E} ;$ roll, $\phi_{E}$ ). 


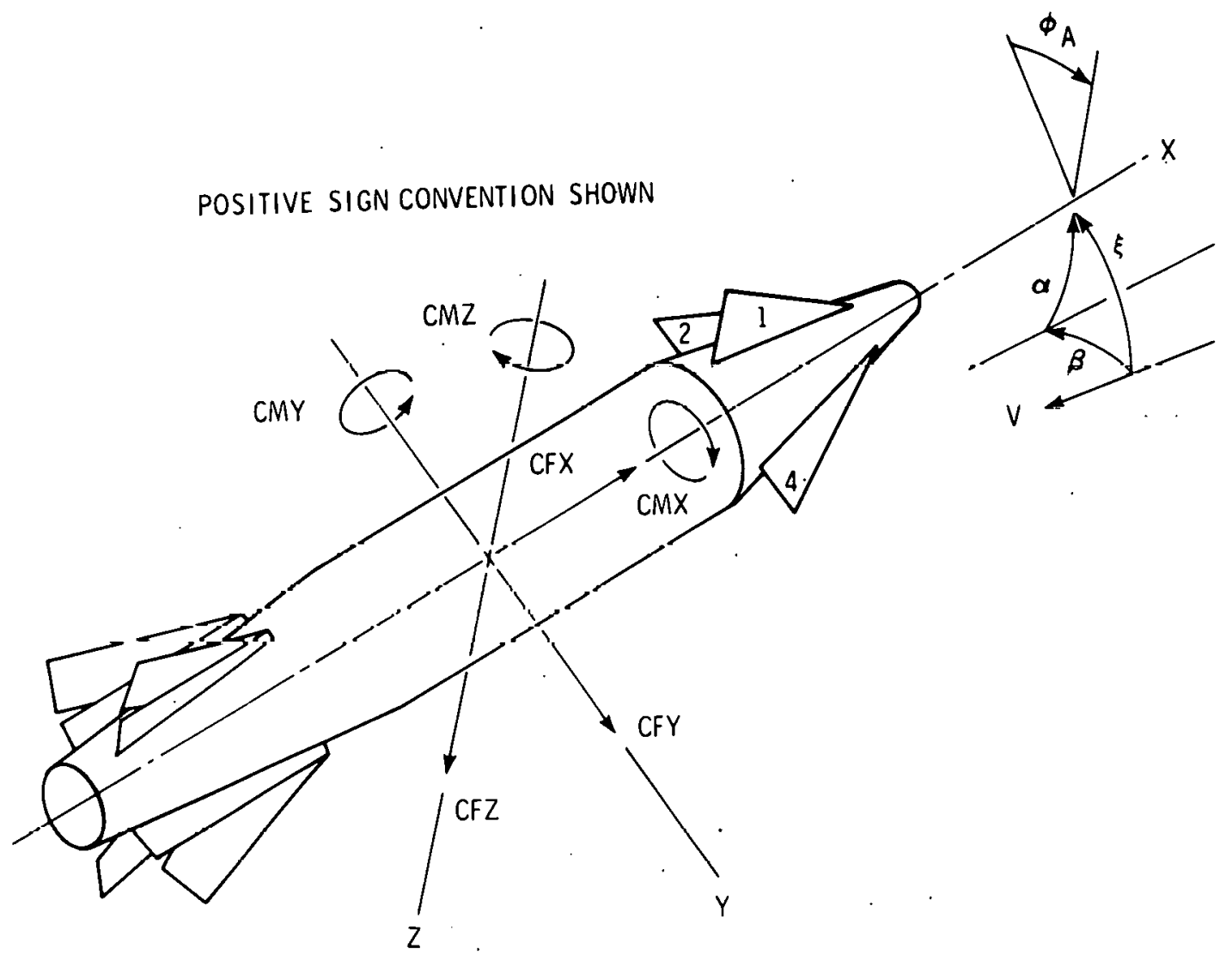

Figure 6. Force and Moment Sign Convention

Velocity and dynamic pressure measurements were simulated by adding in the effect of wind and atmospheric density variations in the same way as in Reference 10 .

\section{Parameter Estimation Results}

When preflight simulation results were compared with flight test data,19 significant differences were observed between the predicted and observed motions. Lateral center-of-mass offset was demonstrated to be a possible source for the difference in roll-rate behavior.

The vehicle model was parameterized to attempt to quantify the effects of inaccurately known vehicle characteristics upon the observed 
differences in motion. The results of estimating various vehicle parameters during the period 9 to $26 \mathrm{~s}$ after release are presented in this section. The simulated data obtained by using the parameter estimates are compared with the flight data in Figures 7 through 16 . During this time segment, the angle-of-attack and angle-of-sideslip are predicted to go through two periods of near constant value (Figures 17 and 18). The aerodynamic roll angle changes from $45^{\circ}$ to $-135^{\circ}$ (Figure 19). The difficulty encountered in consistently predicting rolleron position required using measured rather than simulated rolleron deflection as "control" input. In the initial stages of parameter convergence, measured roll rate was also used as input instead of the computed value to improve the stability of the process. Good agreement between measured and simulated data is achieved. The parameters and their values that were estimated are given in Table 2 .

Estimates of the effects of rollerons were also availablel6 from wind tunnel data and are included in Table 2. The estimates from the flight test indicate that the rollerons were less effective in roll than was indicated by the wind tunnel data. However, since only two rollerons were free to move on ATU-2 any loss of effectiveness caused by wake interference would cause a large percentage error in total rolling moment that could have been partially hidden if all four rollerons were active as in the wind tunnel test. The wind tunnel estimates of $\mathrm{C}_{\mathrm{z}_{\delta}}$ and $\mathrm{C}_{\mathrm{m}_{\delta}}$ were derived from rolling moment and are not direct measurements. 


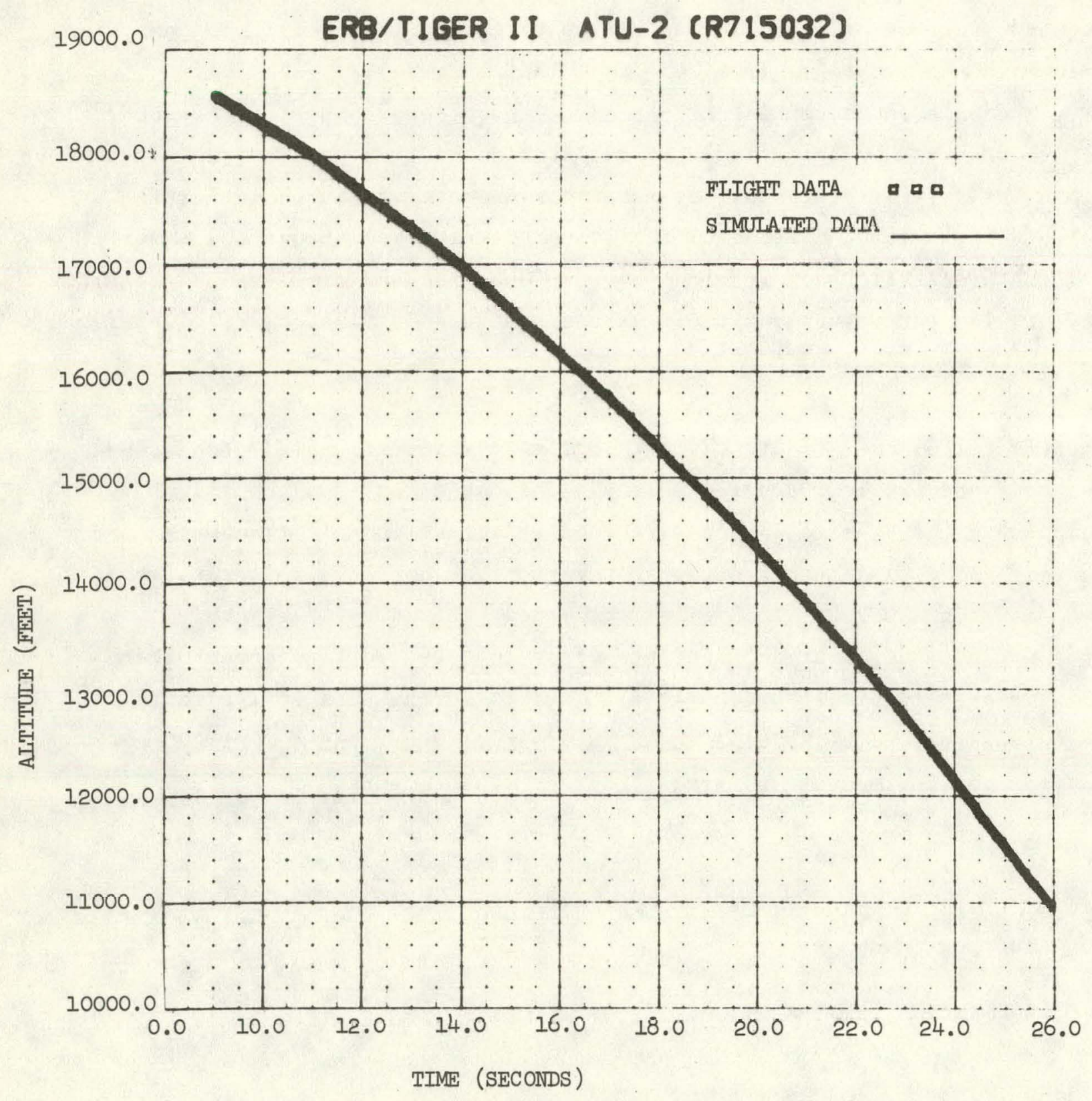

Figure 7. Comparison of Measured and Simulated Altitude Histories 


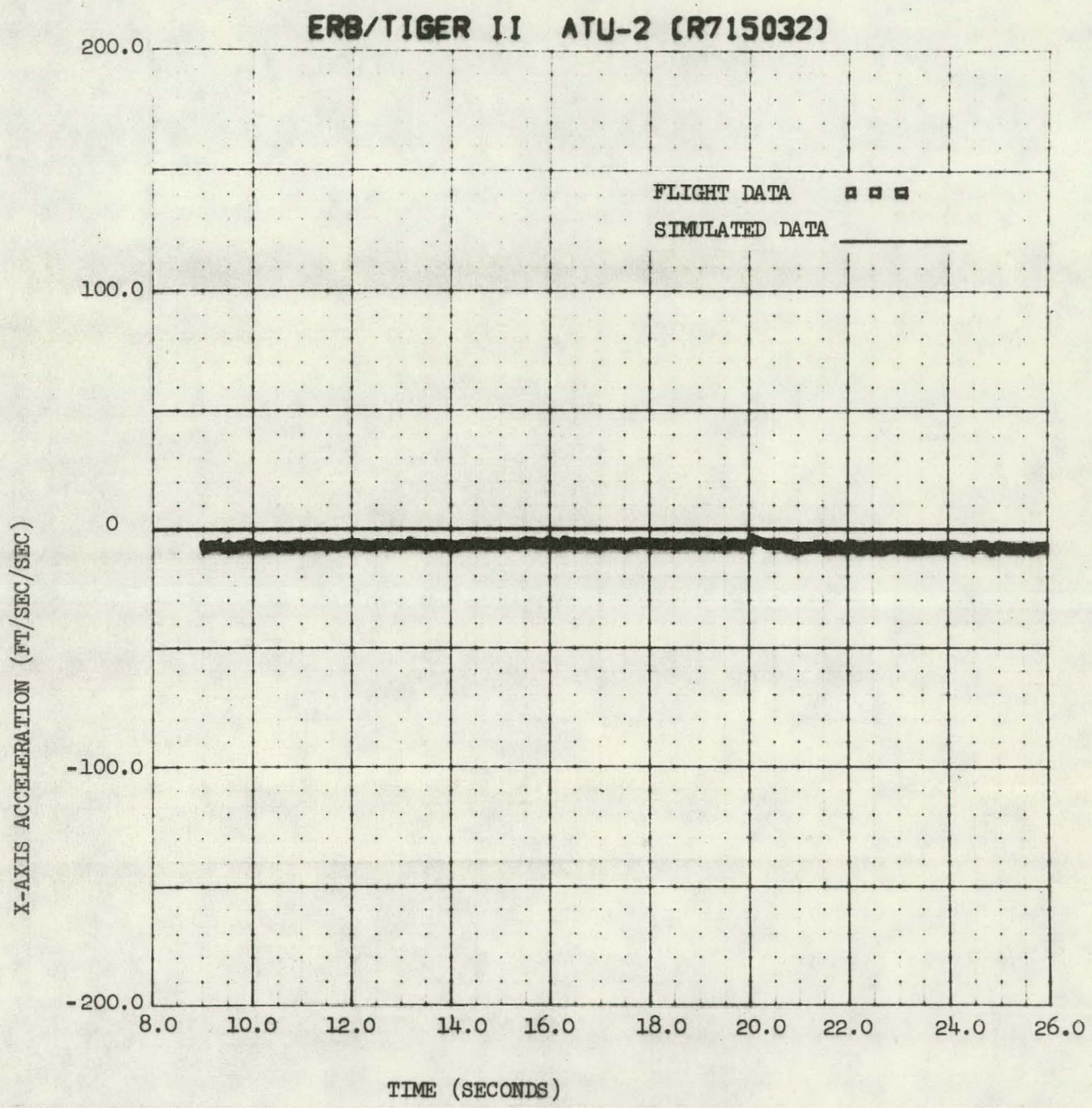

Figure 8. Comparison of Measured and Simulated X-Axis Acceleration Histories 


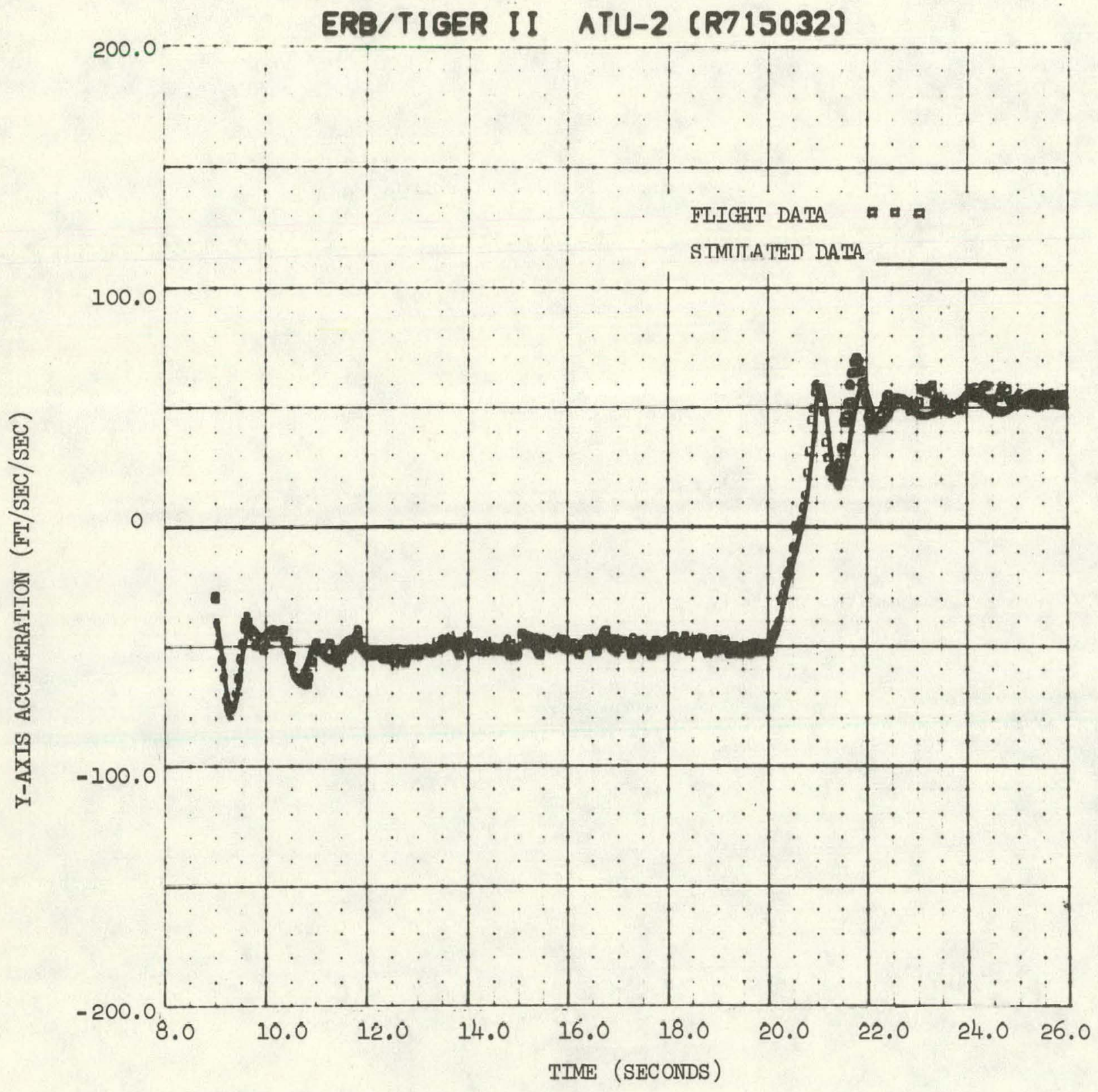

Figure 9. Comparison of Measured and Simulated $\mathrm{Y}-\Lambda \mathrm{xis}$ Acceleration Histories 


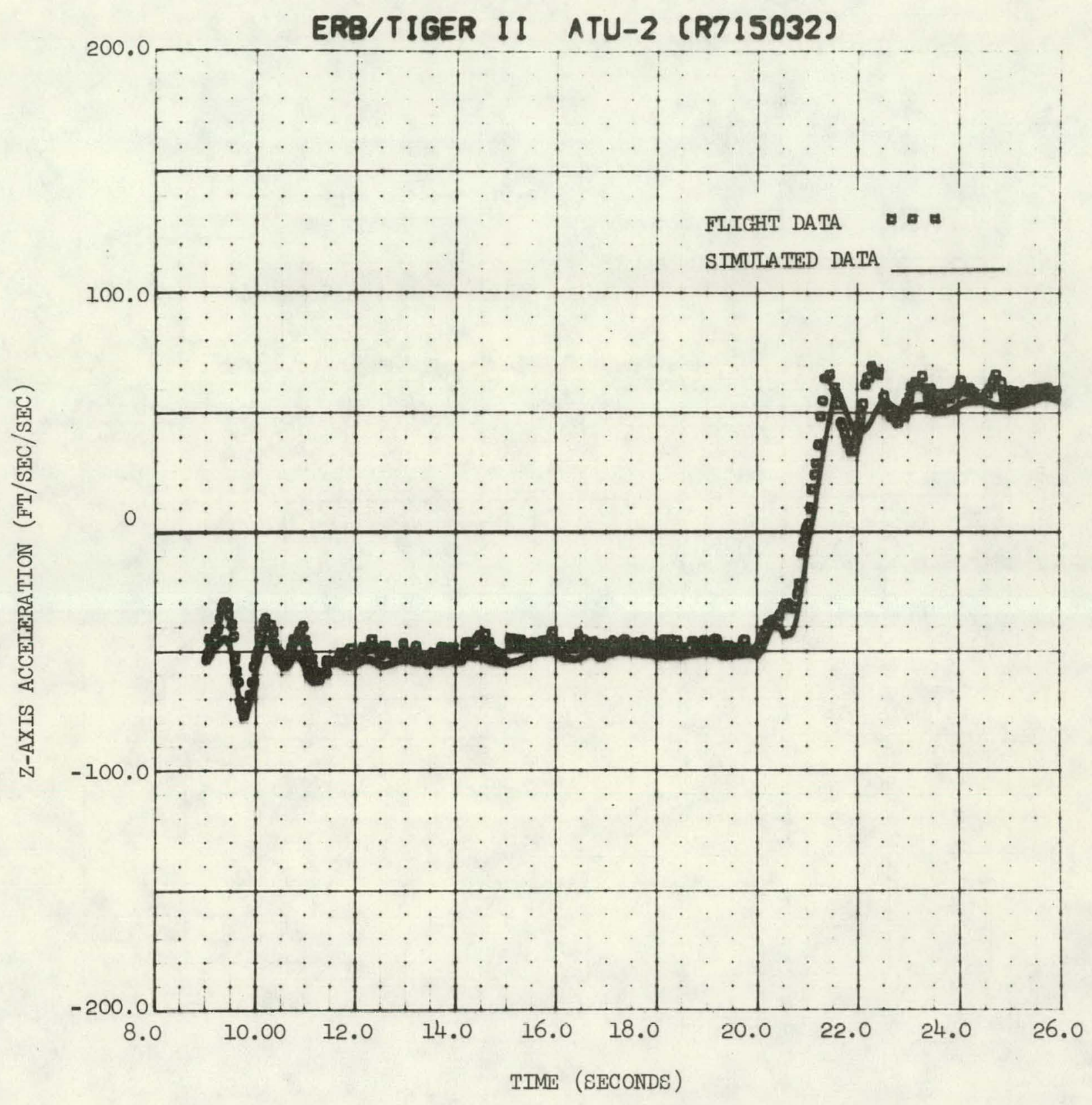

Figure 10. Comparison of Measured and Simulated Z-Axis Acceleration Histories 


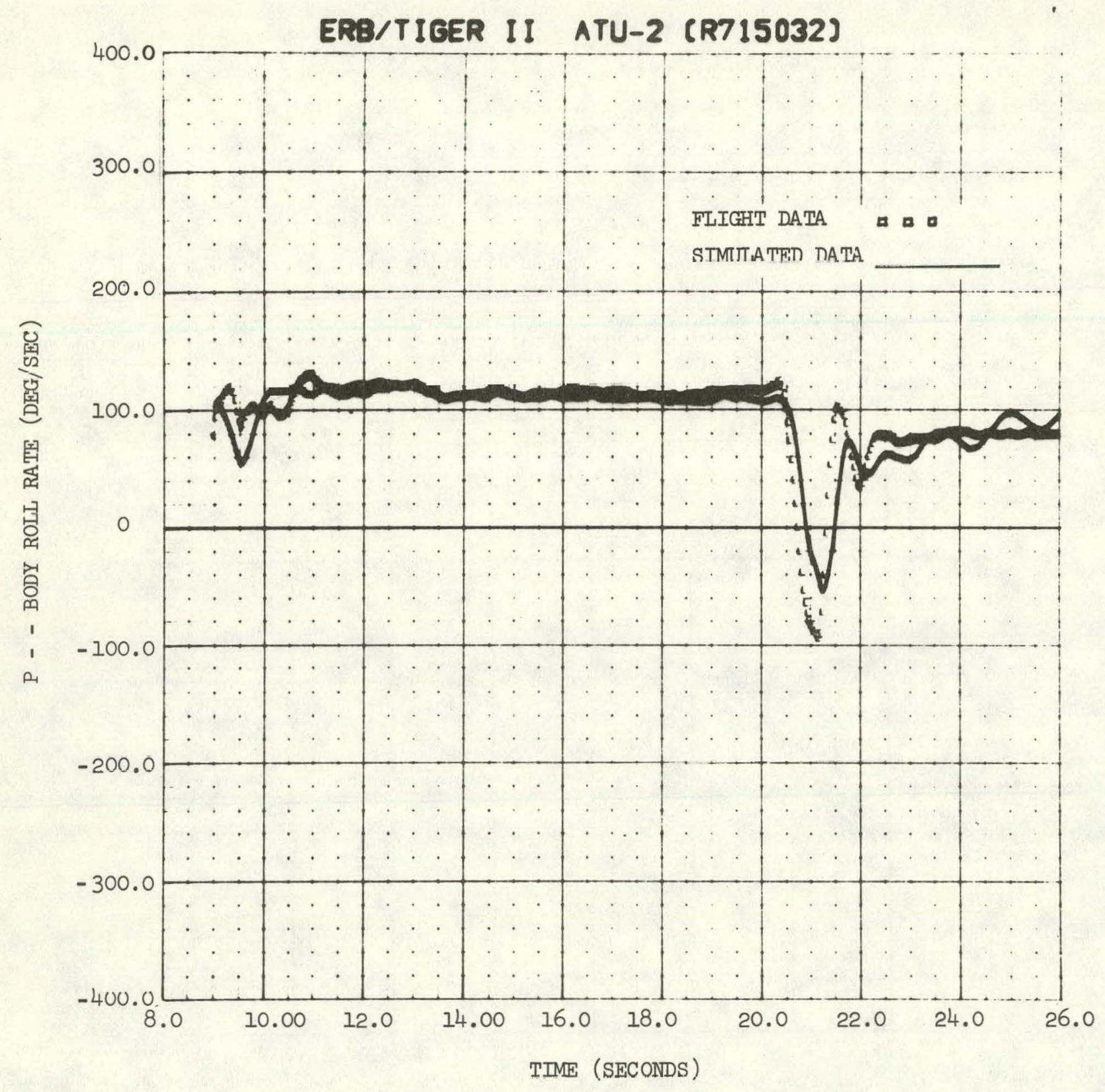

Figure 11. Comparison of Measured and Simulated Body Roll Rate Histories 


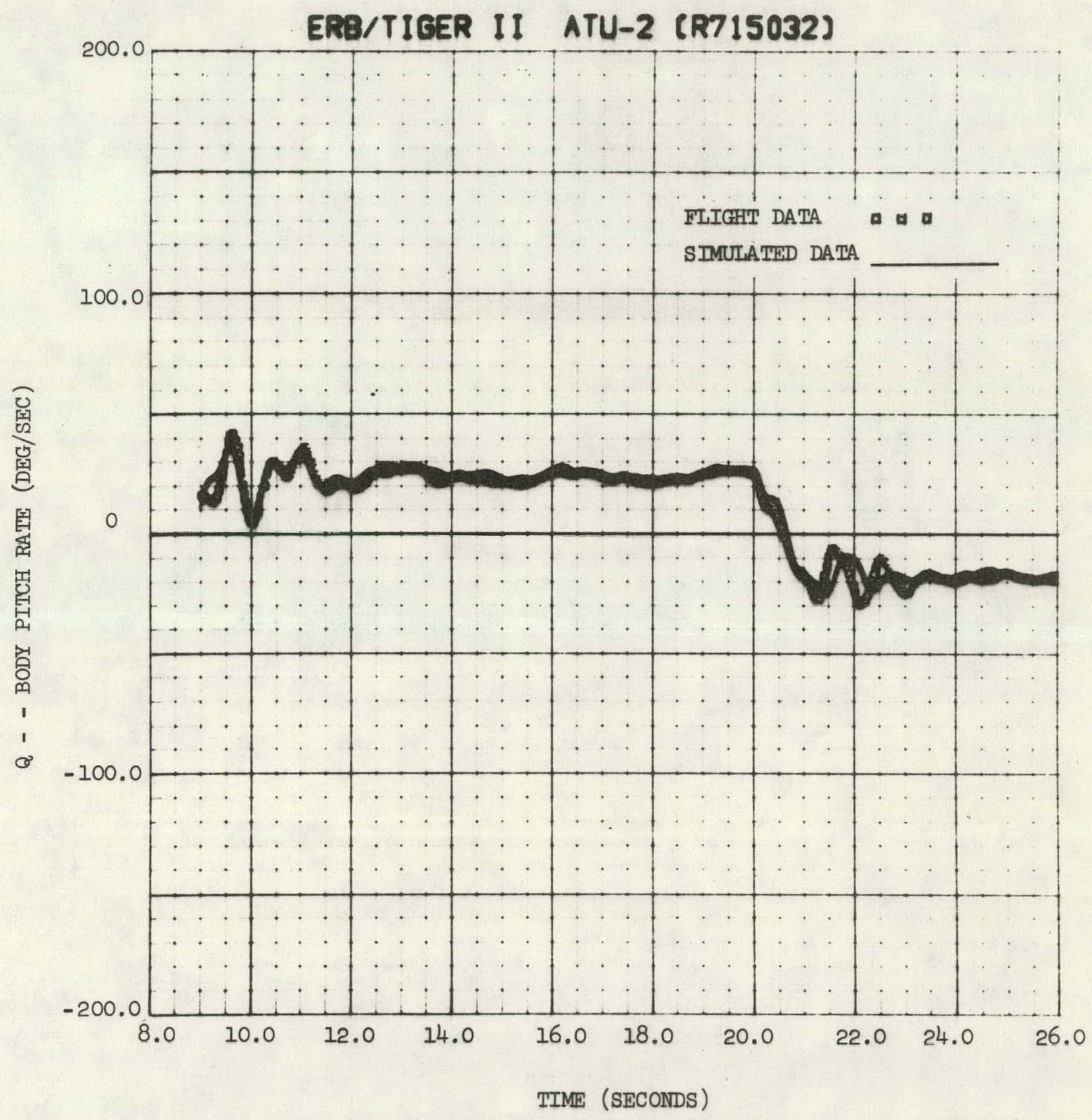

Figure 12. Comparison of Measured and Simulated Body Pitch Rate Histories 


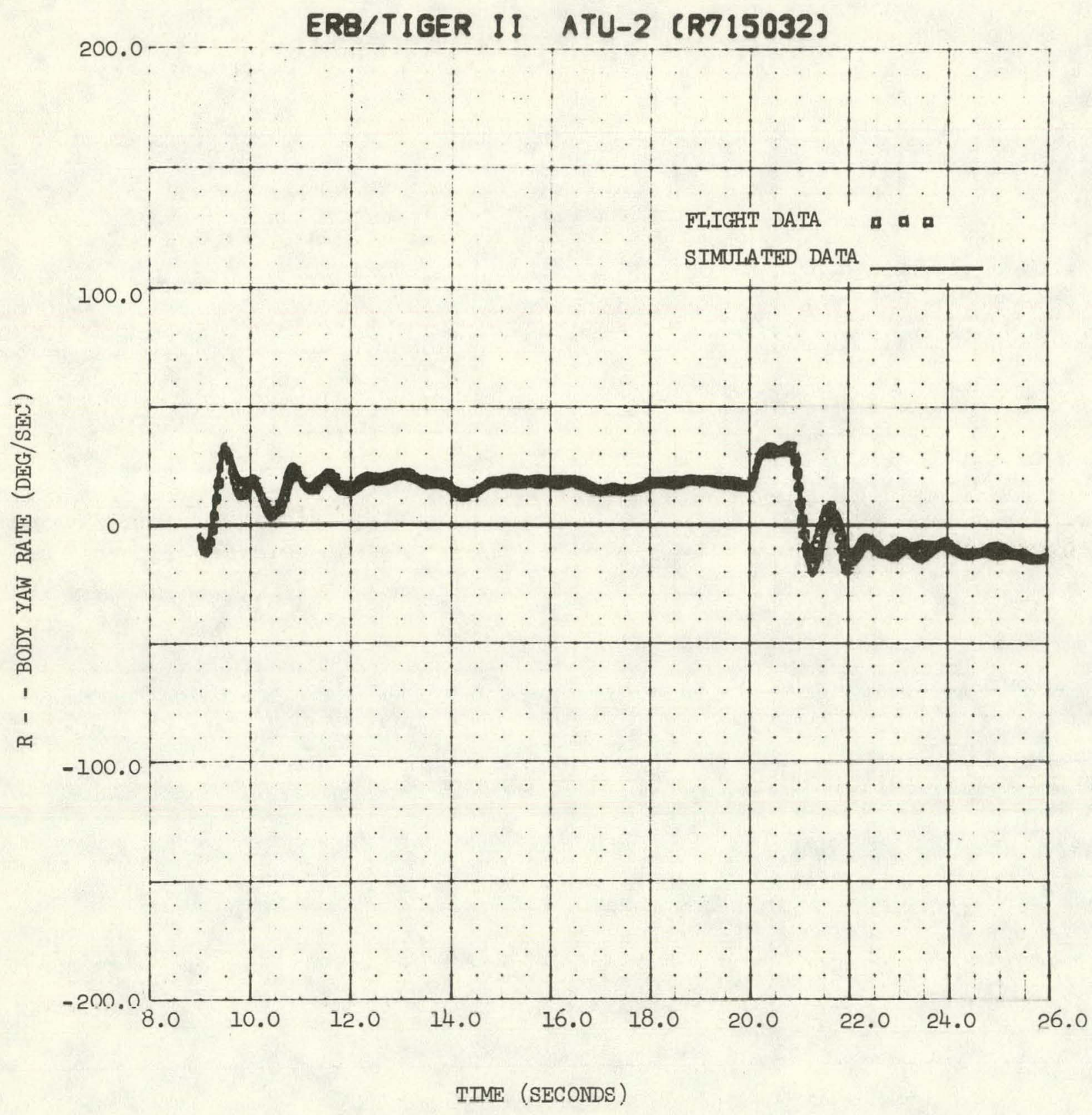

Figure 13. Comparison of Measured and Simulated Body Yaw Rate Histories 


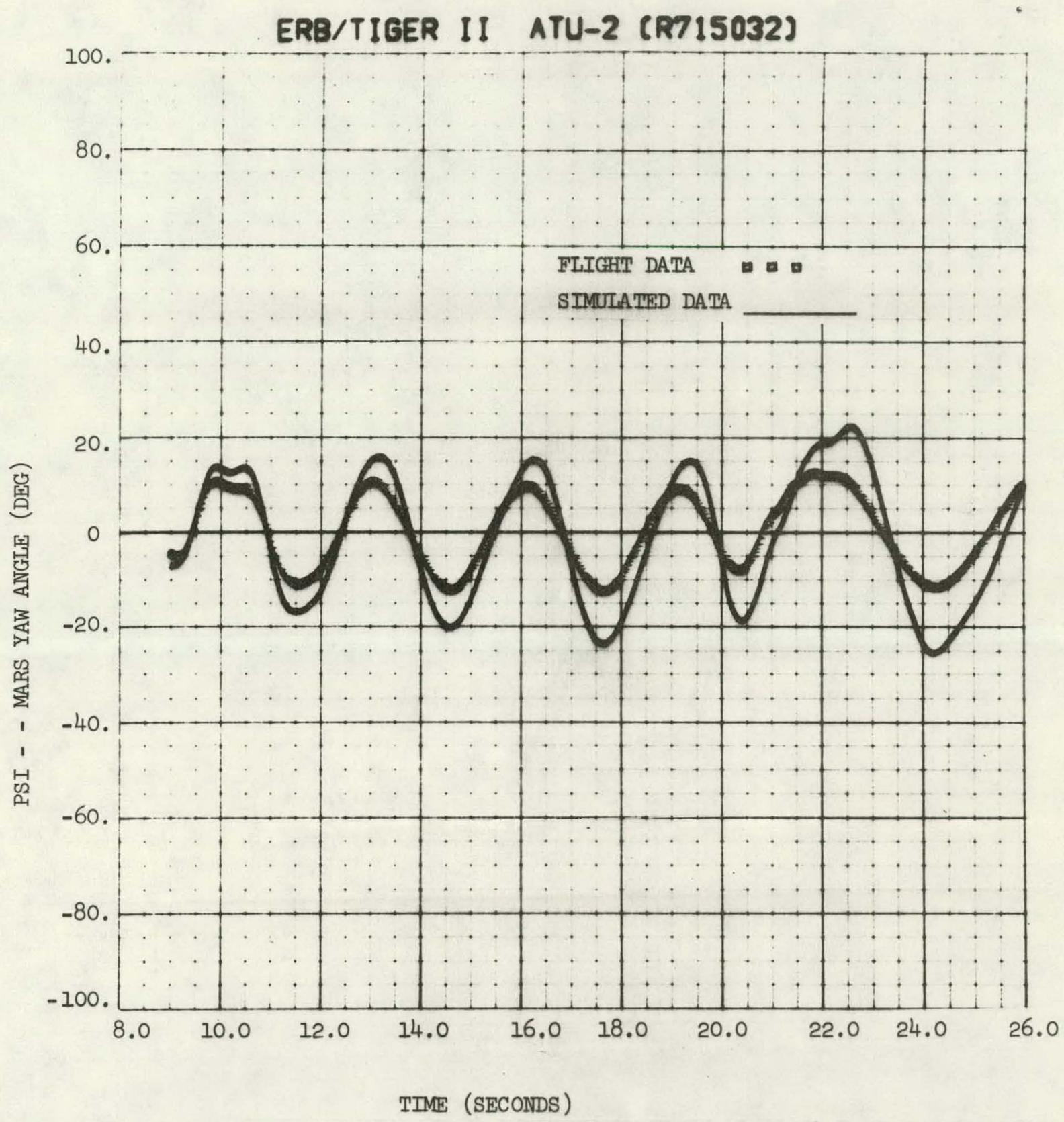

Figure 14. Comparison of Measured and Simulated MARS Yaw Angle Histories 


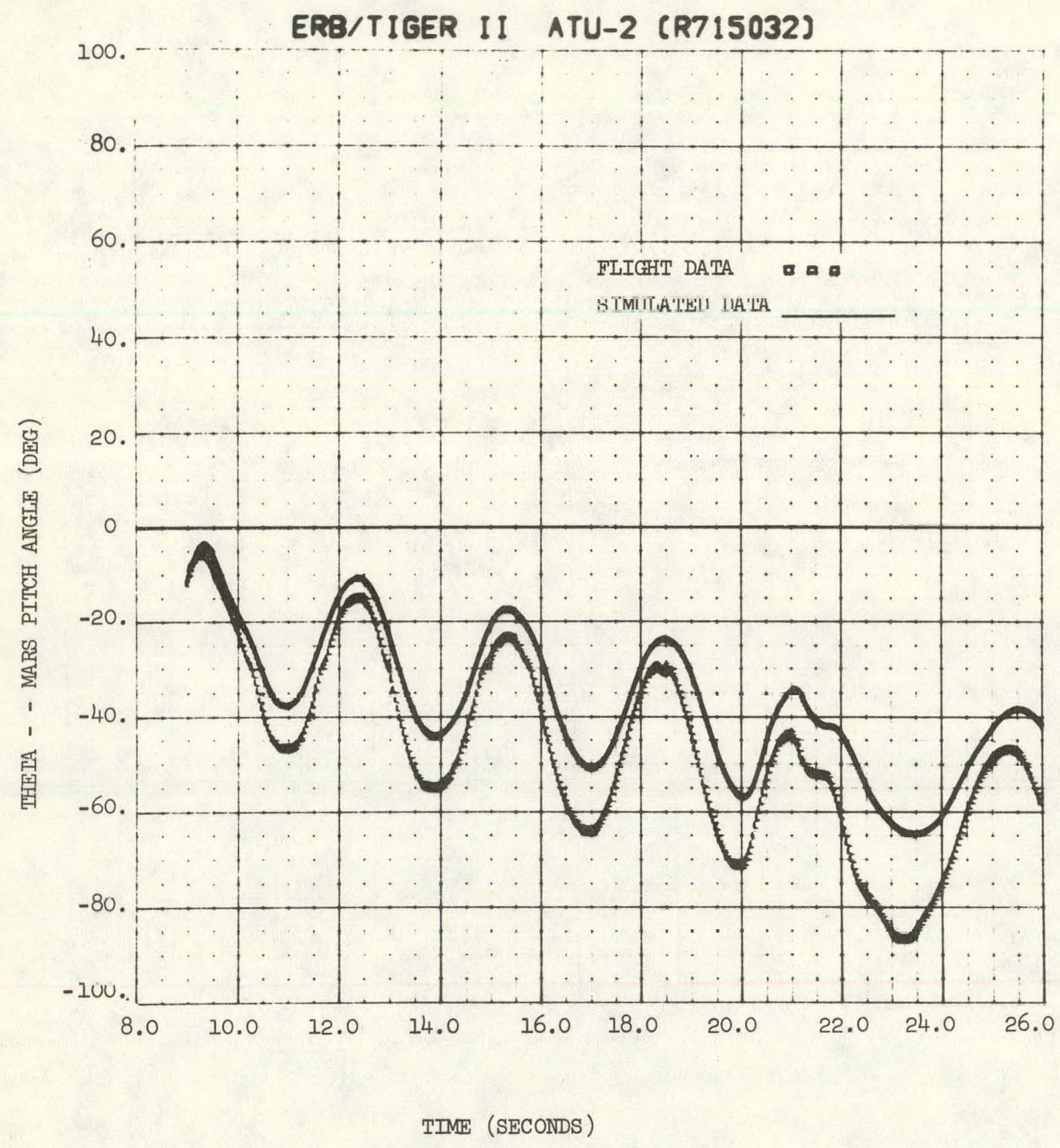

Figure 15. Comparison of Measured and Simulated MARS Pitch Angle Histories 




Figure 16. Comparison of Measured and Simulated MARS Roll Angle Histories 


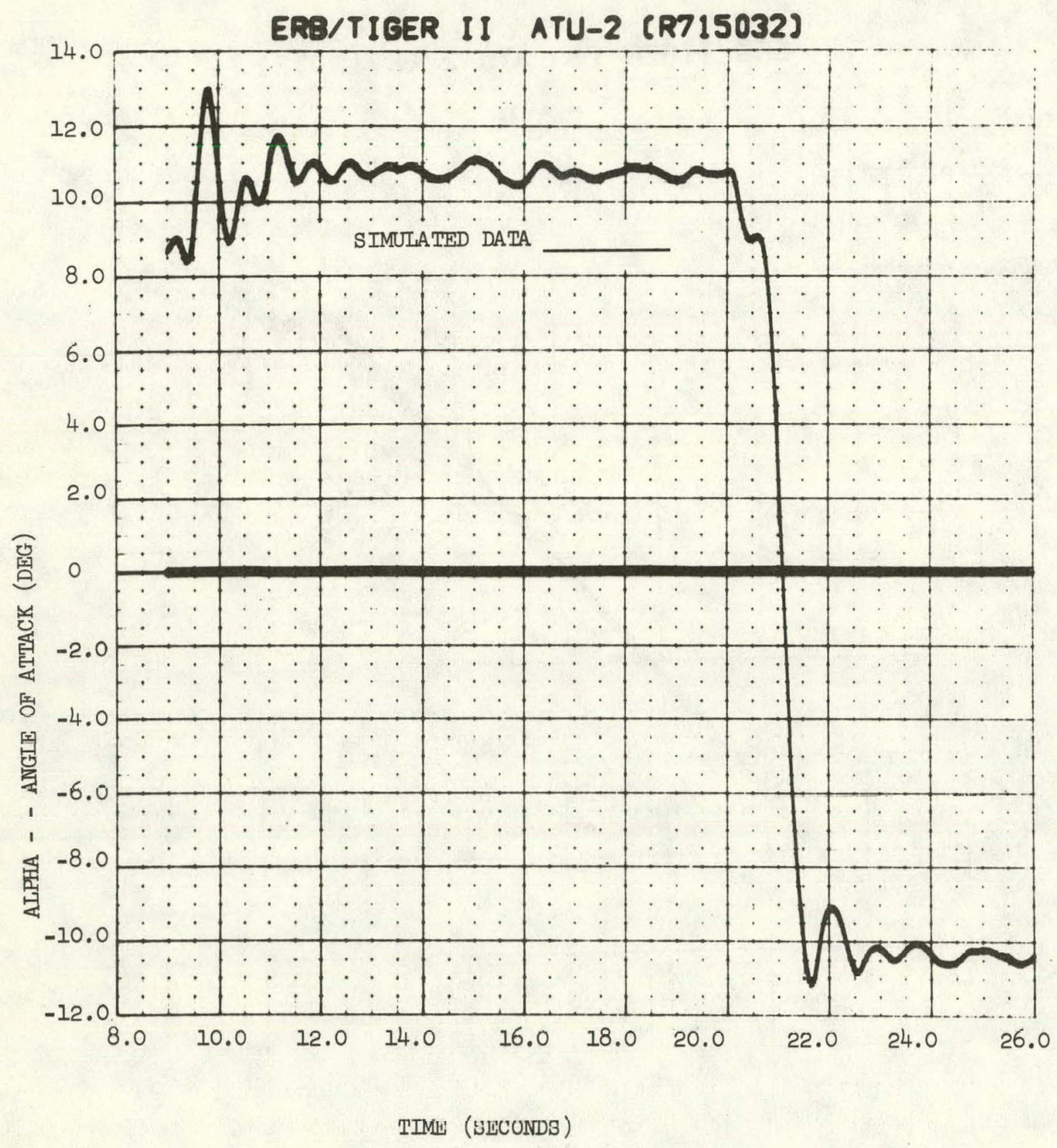

Figure 17. Angle-of-Attack History Generated by Simulated Trajectory 


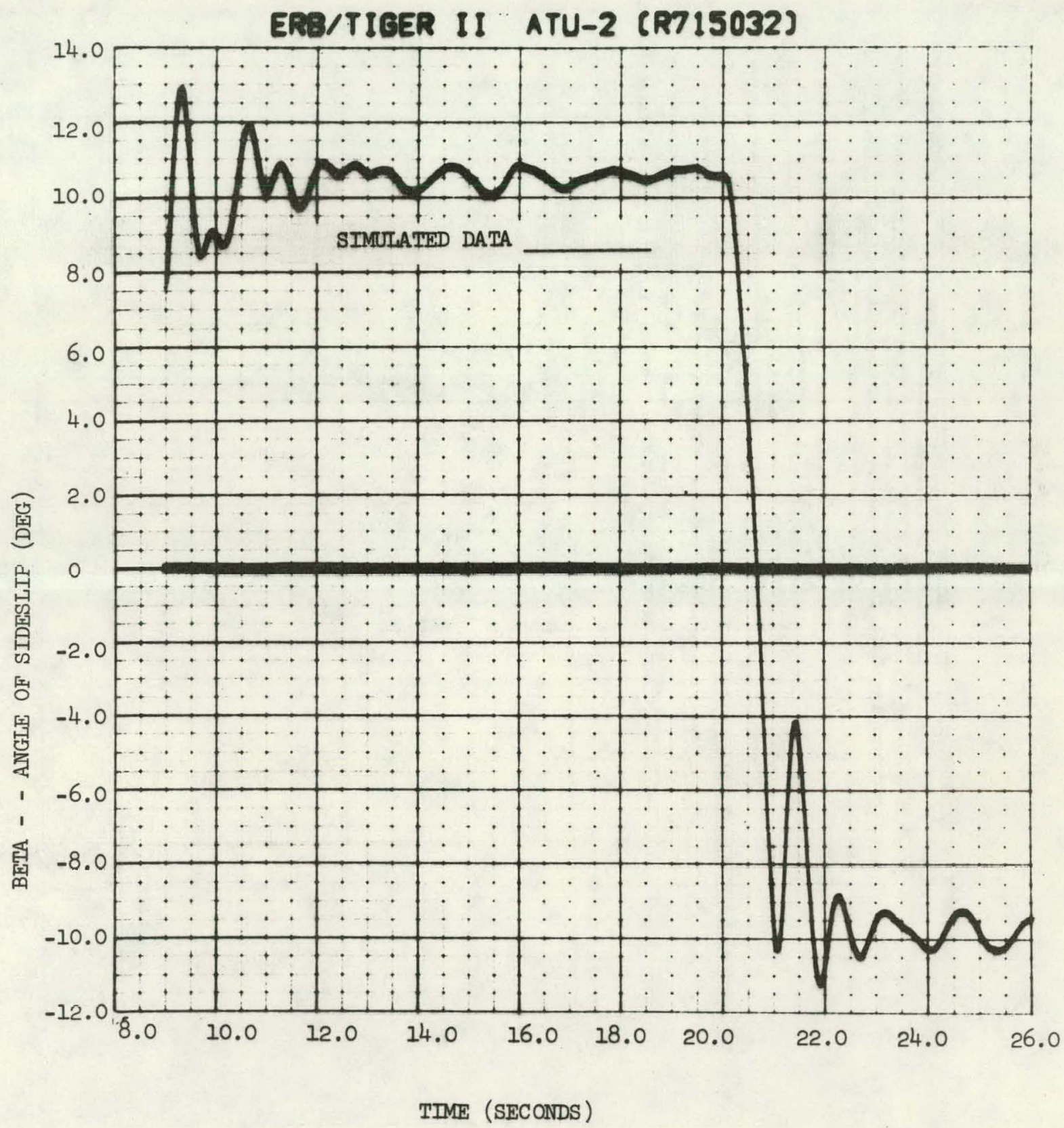

Figure 18. Angle-of-Sideslip History Generated by Simulated Trajectory 




Figure 19. Aerodynamic Roll Angle History Reconstructcd From Lateral Acceleration Measurements 
Table 2

Comparison of Flight Test and Wind Tunnel Estimates

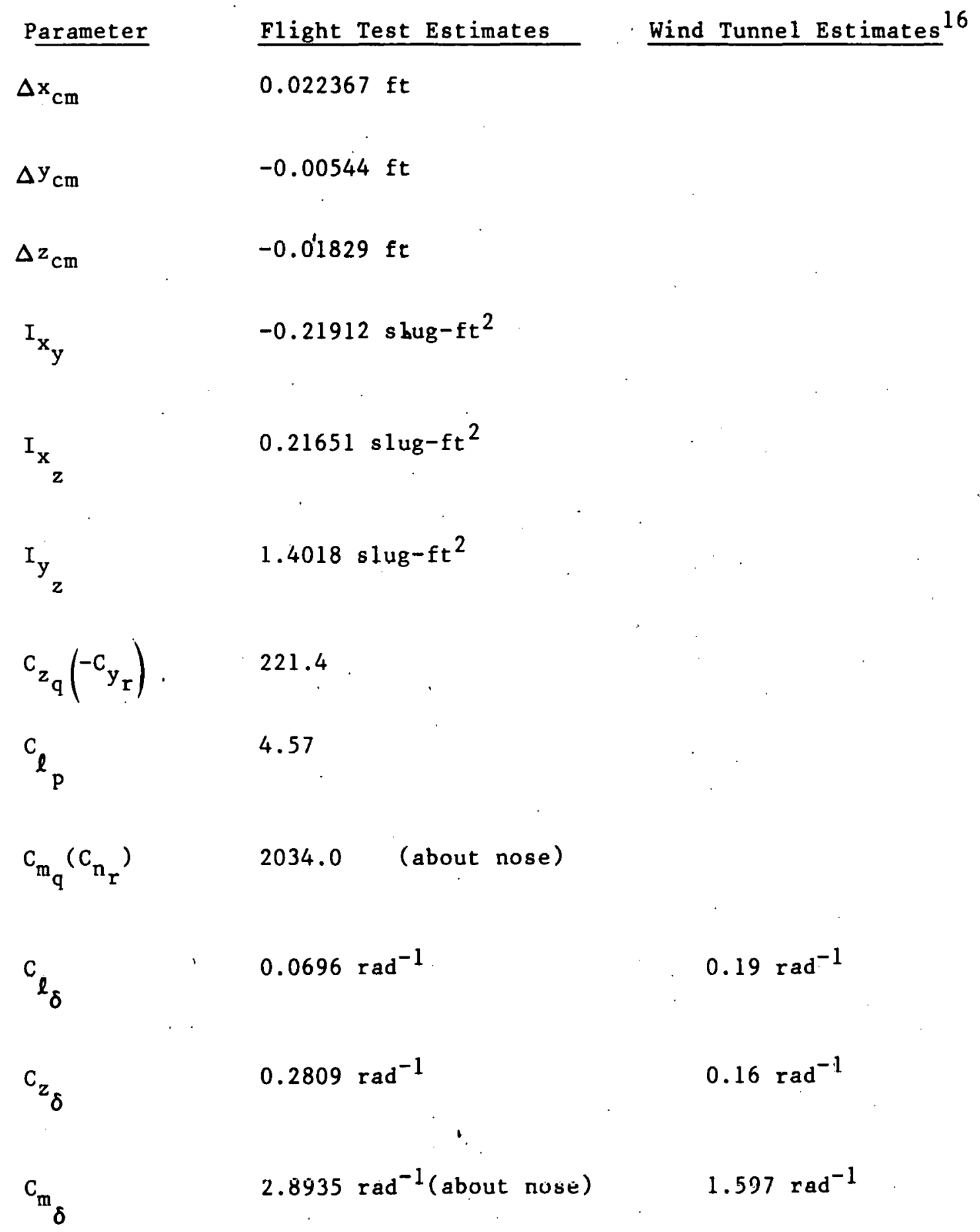


Based on the preceding analysis, the following conclusions were reached.

- The rollerons have a destabilizing effect upon vehicle pitch and yaw stability as evidenced by the differing pitch and yaw frequencies.

- The tabular wind tunnel data are sufficiently accurate to predict behavior for the flight conditions of ATU-2 if rolleron and centerof-mass offset efferts are included.

- Rolleron models that ignore the effects of wake interference do not accurately predict rolleron motion.

- Parameter estimates were obtained for dynamic derivatives which improved the agreement between flight and simulation results.

- The small rolleron deflections in response to roll rate $(\sim 100$ $\mathrm{deg} / \mathrm{s})$ indicate the need to reevaluate the rolleron/tail fin configuration to minimize rolleron deflection sensitivity to local angle-of-attack and improve roll damping effectiveness.

- Release and separation-characteristics of the vehicle were as expected.

- The recovery system performed as expected.

\section{References}

${ }^{1}$ C.S. Callender, ERB Drop Test R800278 - Data Reduction Report

(Trajectory), Test Data Analysis Division (Albuquerque: Sandia

Laboratories, Test Date July 23, 1976, at Tonopah Test Range).

2G. G. Wilson to C. E. Dalton, "A Partial Assessment of the Data Requirements for the ERB Program - ATU Flight," (Albuquerque: Sandia Laboratories, March 18, 1976). Memorandum.

${ }^{3}$ G. G. Wilson to C. E. Dalton, "Results of ERB-ATU F1ight Test Data Reduction," (Albuquerque: Sandia Laboratories, December 15, 1976). Memor and um .

${ }^{4}$ C. S. Callender, ERB Guided Flight Test (FTU-2) R800771 - Data Reduction Report (Trajectory) Test Data Analysis Division, (Albuquerque: Sandia Laboratories, Test Date July 9, 1977, at Tonopah Test Range). 
${ }^{5}$ G. M. Ferguson to C. E. Dalton, "FTU-2 Flight Test Results," (Albuquerque: Sandia Laboratories, November 22, 1977). Memorand um.

${ }^{6} \mathrm{H}$. R. Vaughn to C. E. Dalton, "Flight Dynamics Behavior of FTU-2, "Albuquerque: Sandia Laboratories, September 14, 1977). Memorandum.

${ }^{7}$. E. Diesing, "Mass Properties TIGER II/ATU-2," (Albuquerque: Sandia Laboratories, August 19, 1977). Memorandum.

${ }^{8}$ R. C. Maydew, Aerodynamic Design of an Extended Range Bomb, SAND790836, (Albuquerque: Sandia Laboratories, 1979).

${ }^{9}$ A. E. Brown, Wind-Tunnel Tests of the SW-IC Rolleron with $45^{\circ}$ Canted Hinge Line, Data Presentation, Technical Note 4063-111 (informal report), (China Lake, CA: U. S. Naval Ordnance Test Station, May 1962).

10W. M. Ward, ERB/ATU-2 R715032 - Data Reduction Report (Trajectory), Test Data Analysis Division Albuquerque: Sandis Laboratories, Test Date August 25, 1977, at Tonopah Test Range).

$11_{M}$. Goddard, ERB/ATU2 R715032 - Telemetry Data Plots, Test Data Analysis Division (Albuquerque: Sandia.Laboratories, Test Date August 25, 1977, at Tonopah Test Range).

$12 \mathrm{D}$. S. W. Barnette, Transonic Wind Tunnel Test of the Sandia TIGER II, SAND78-0542 (Albuquerque: Sandia Laboratories, 1978).

13 N. A. Struznski, Transonic Wind Tunnel Force Tests of the Sandia TIGER II Model in the CALSPAN 8-foot Transonic Wind Tunnel, CALSPAN Report No. AA-4034-W-2, W. A. T34-073, 3 vols., (Buffalo, NY: CALS PAN Corp., July, 1976).

${ }^{14}$ E. L. Clark, "ERB TWT Test III-195," (Albuquerque: Sandia Laboratories, May 12, 1977). Memorandum.

${ }^{15}$ D. W. Barnette, Transonic Wind Tunnel Test of the Sandia TIGER II With Free-Floating Rollerons, SAND78-0543 (Albuquerque: Sandia Laboratories, 1978).

${ }^{16}$ R. W. Greene to G. M. Ferguson, "Effect of Free-Floating Rollerons on 13.3 Vehicle Aerodynamics," (Albuquerque: Sandia Laboratories, October 27, 1977). Memor and um.

${ }^{17} \mathrm{~V}$. J. Roh, to Distribution "TM Data List for the ATU-II Vehicle," (Albuquerque: Sandia Laboratories, June 7, 1977). Memorandum.

${ }^{18}$ G. M. Ferguson and R. J. Luikens, "FTU-1 Data," (Albuquerque: Sandia Laboratories, April 25, 1977). Memorandum.

${ }^{19} \mathrm{G}$. M. Ferguson, to Distribution "ATU-2 Post Flight Results," (Albuquerque: Sandia Laboratories, January 17, 1978). Memorandum. 
20 . W. Greene, to Distribution Rolleron Dynamic Performance on TIGER II, SAND80-0131, (Albuquerque:- Sandia Laboratories, 1980).

$21_{\text {W. }}$ E. Williamson, "Square Root Variable Metric Method for Function Minimization," AIAA Journal, 13:107-9, January 1975.

22L. D. Gillette, to Distriution "Utilization of MARS Platforms," (Albuquerque: Sandia Laboratories, June 22, 1977). Memorandum. 
APPENDIX

ATU-2 F1ight Test Data

45-46 




Figure A-1 Variation of Atmospheric Density With Altitude (A TU-2) 


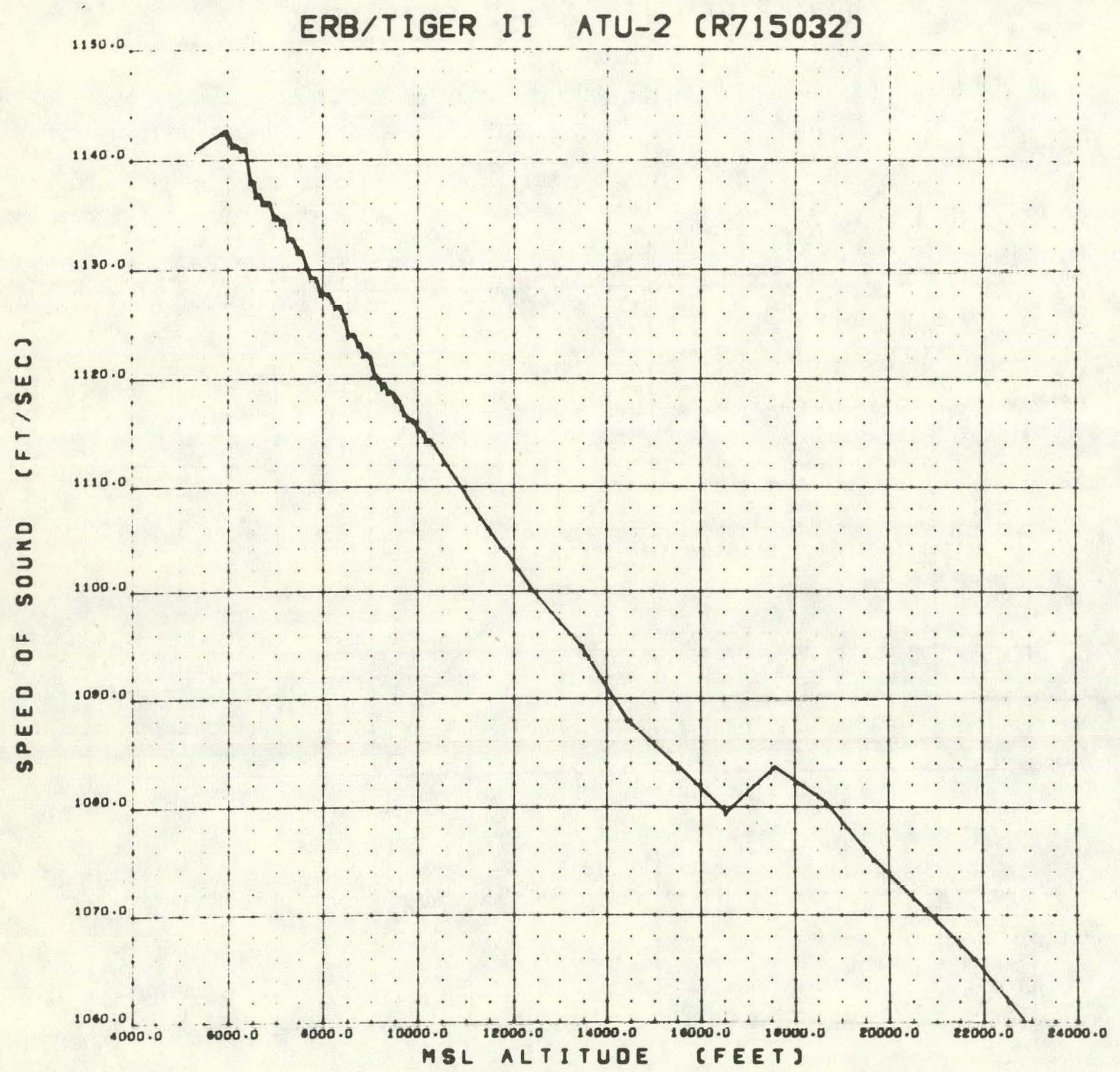

Figure A-2 Variation of Speed of Sound With Altitude (ATU-2) 


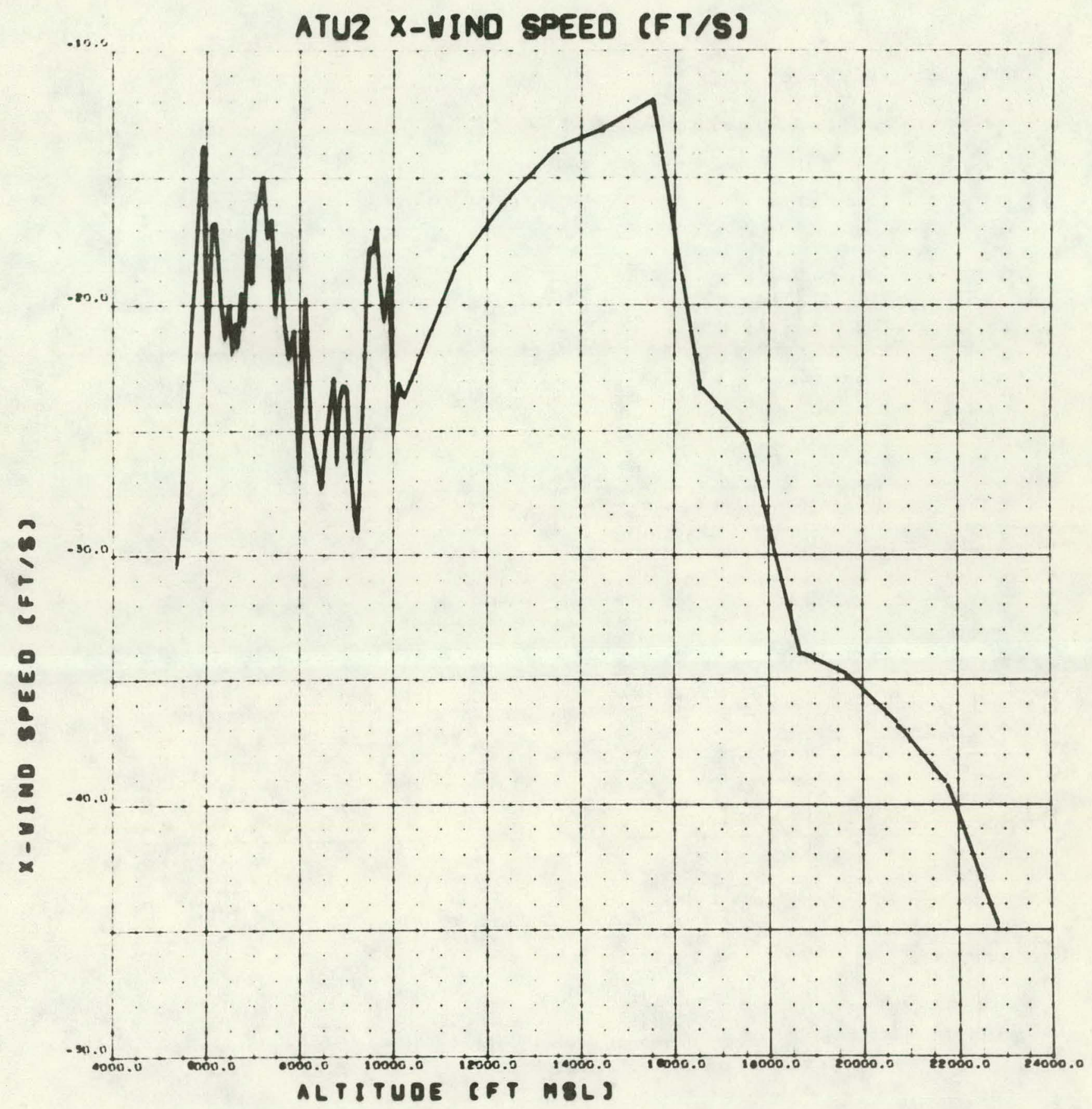

Figure A-3 Variation of Downrange Wind Speed With Altitude (A TU-2) 


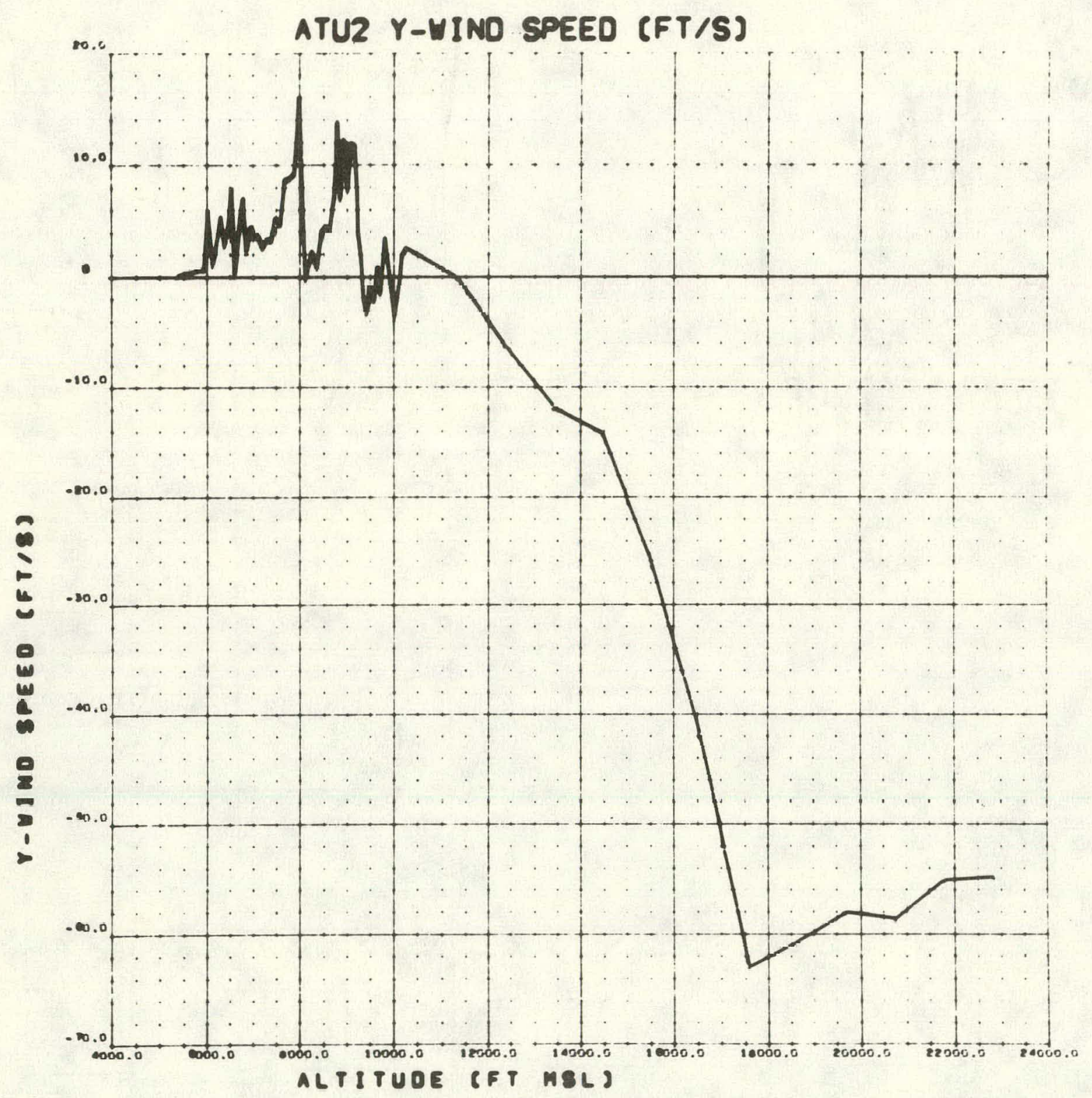

Figure A-4 Variation of Crossrange Wind Speed With Altitude (ATU-2) 


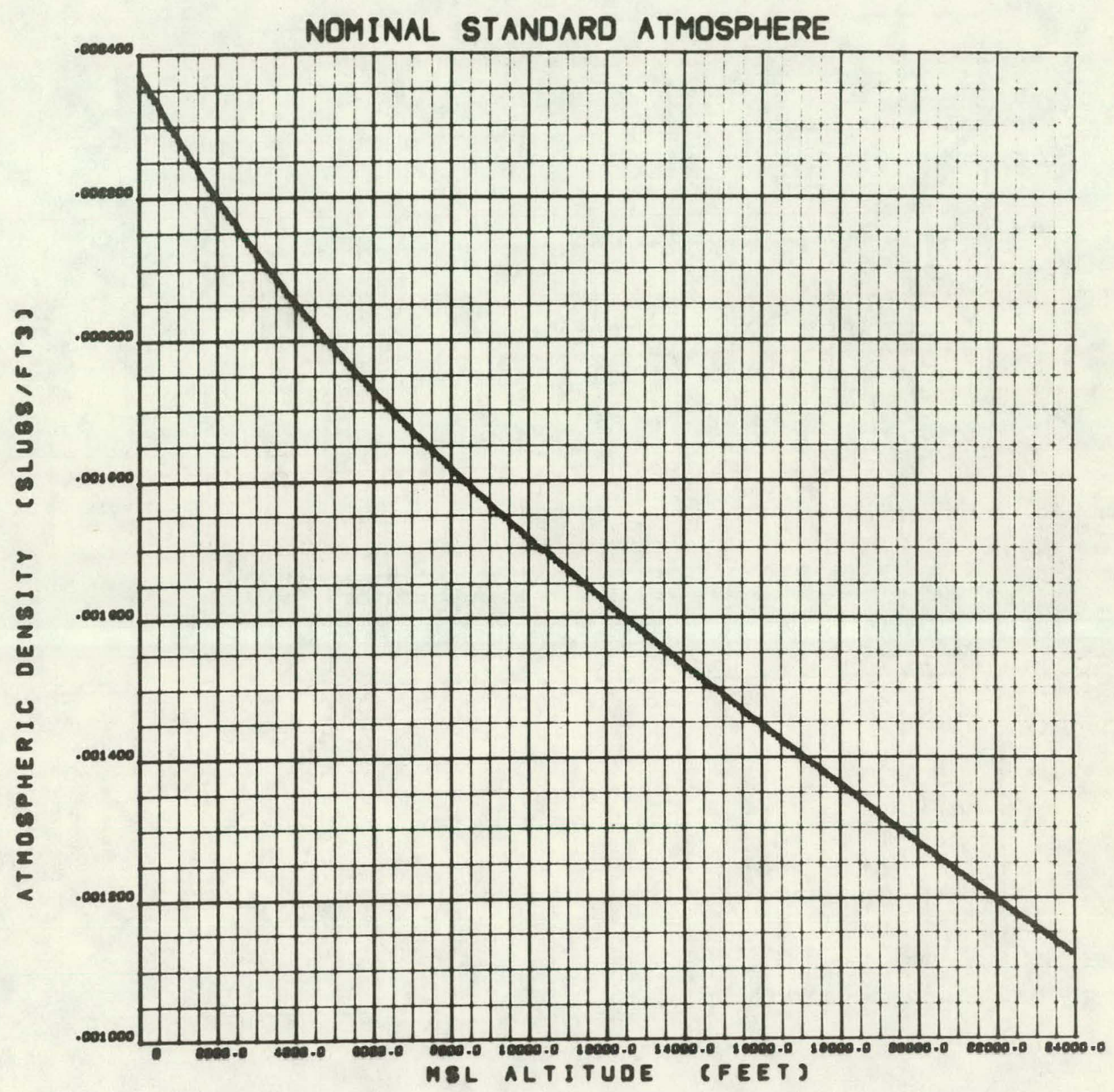

Figure A-5 Variation of Density With Altitude (Standard Atmosphere) 


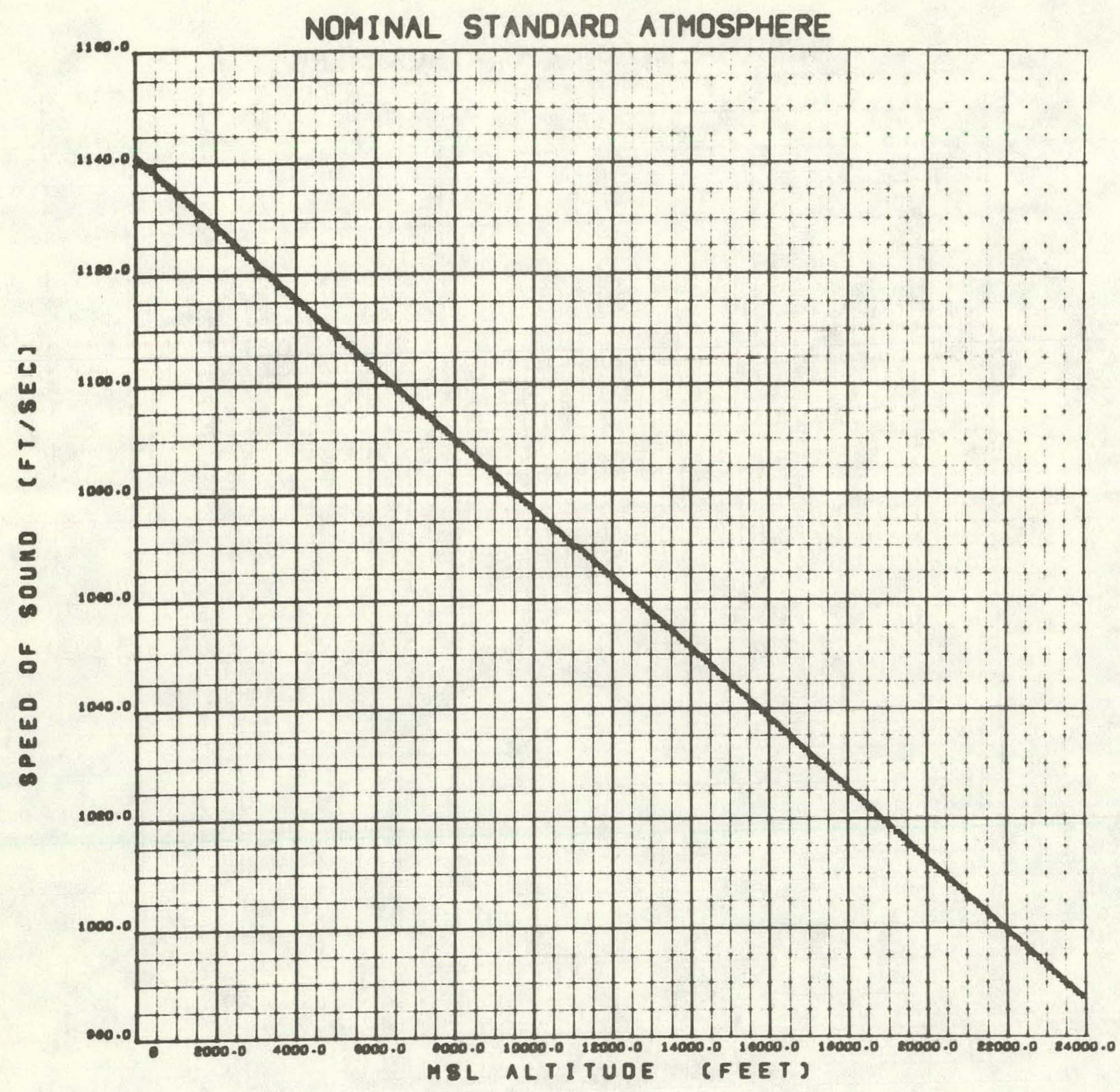

Figure A-6 Variation of Speed of Sound With Altitude (Standard Atmosphere) 


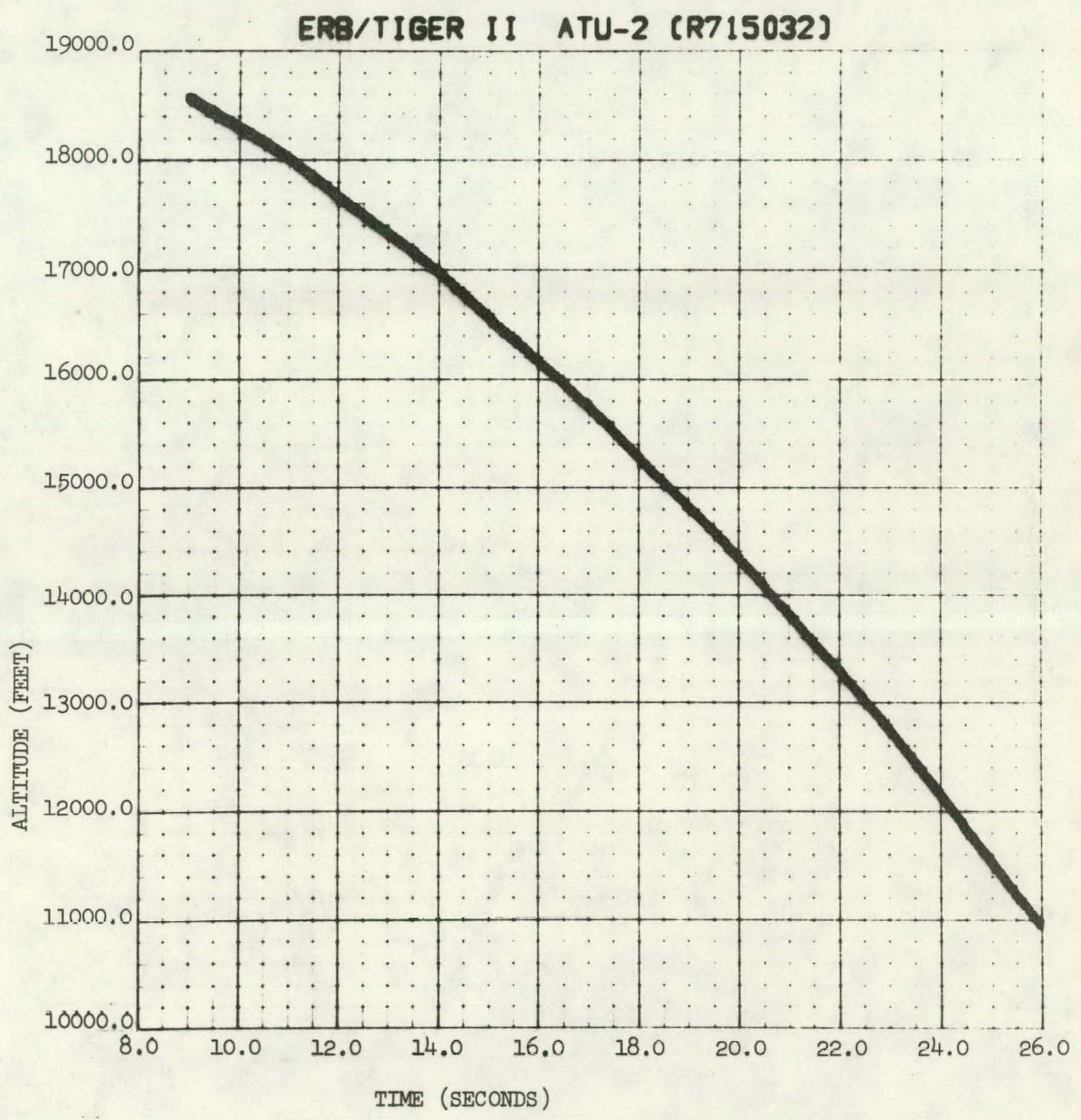

Figure A-7 Altitude vs Time From Release 


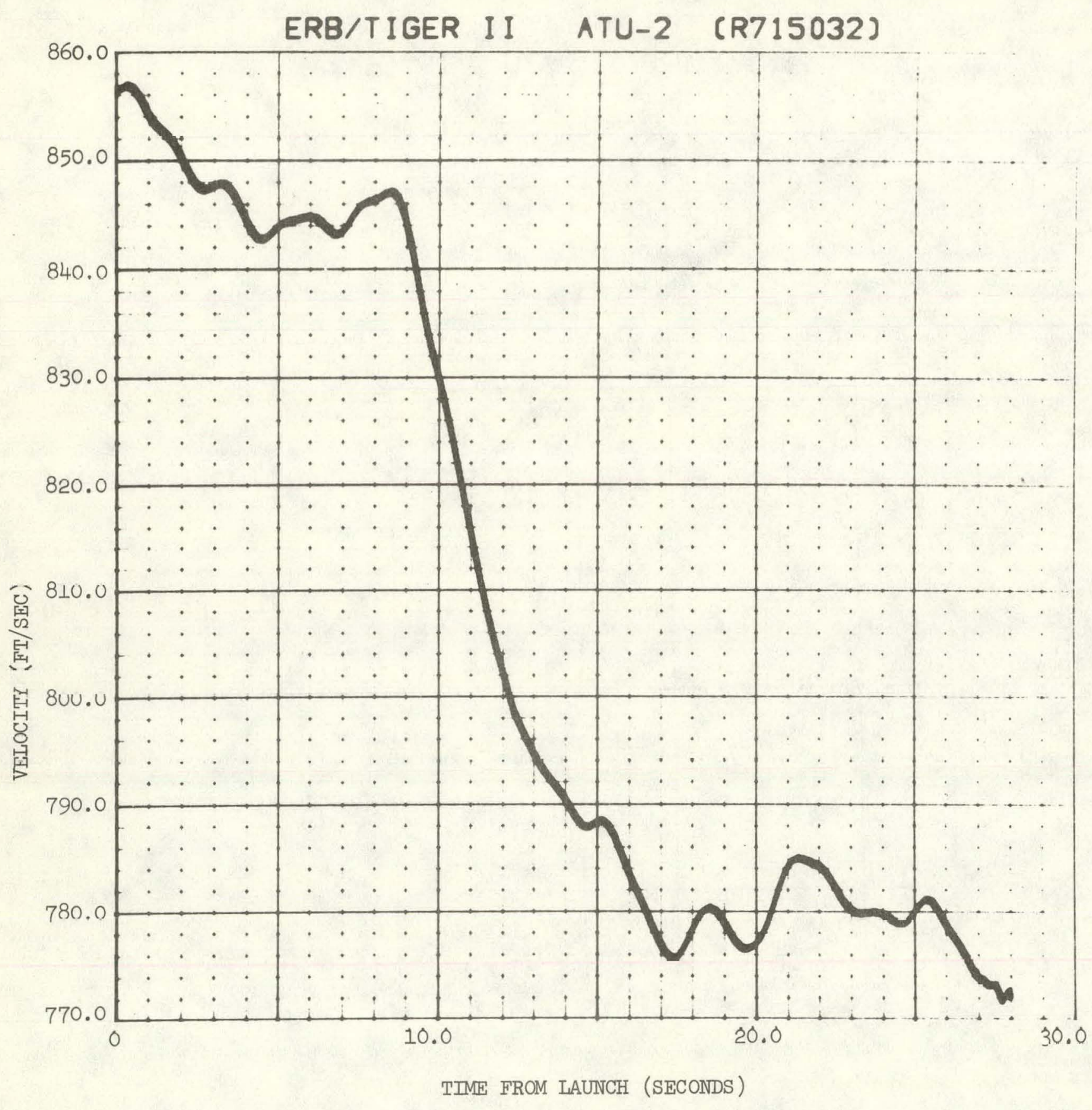

Figure A-8 Velocity vs Time From Release 


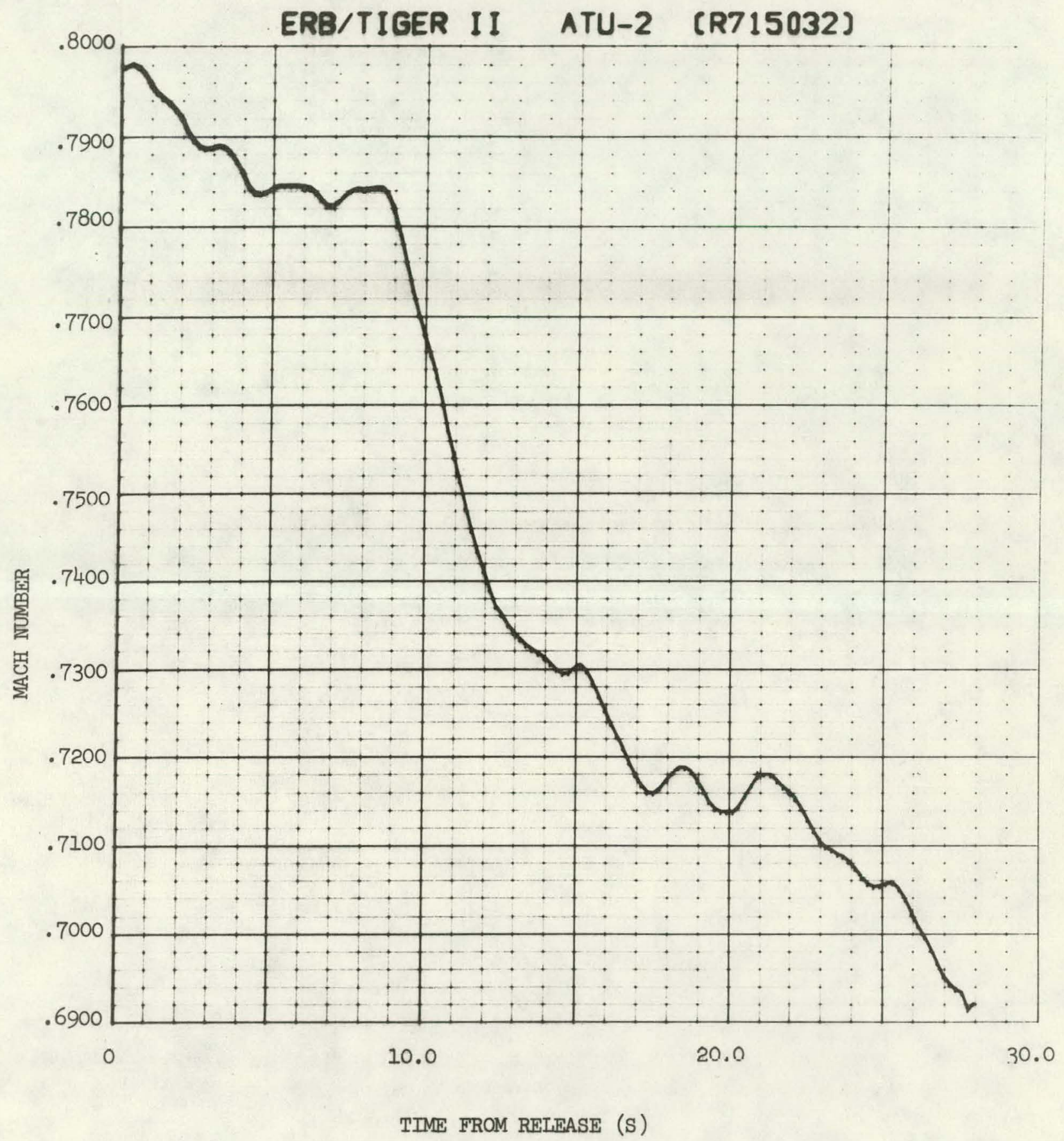

Figure A-9 Mach Number vs Time From Release 


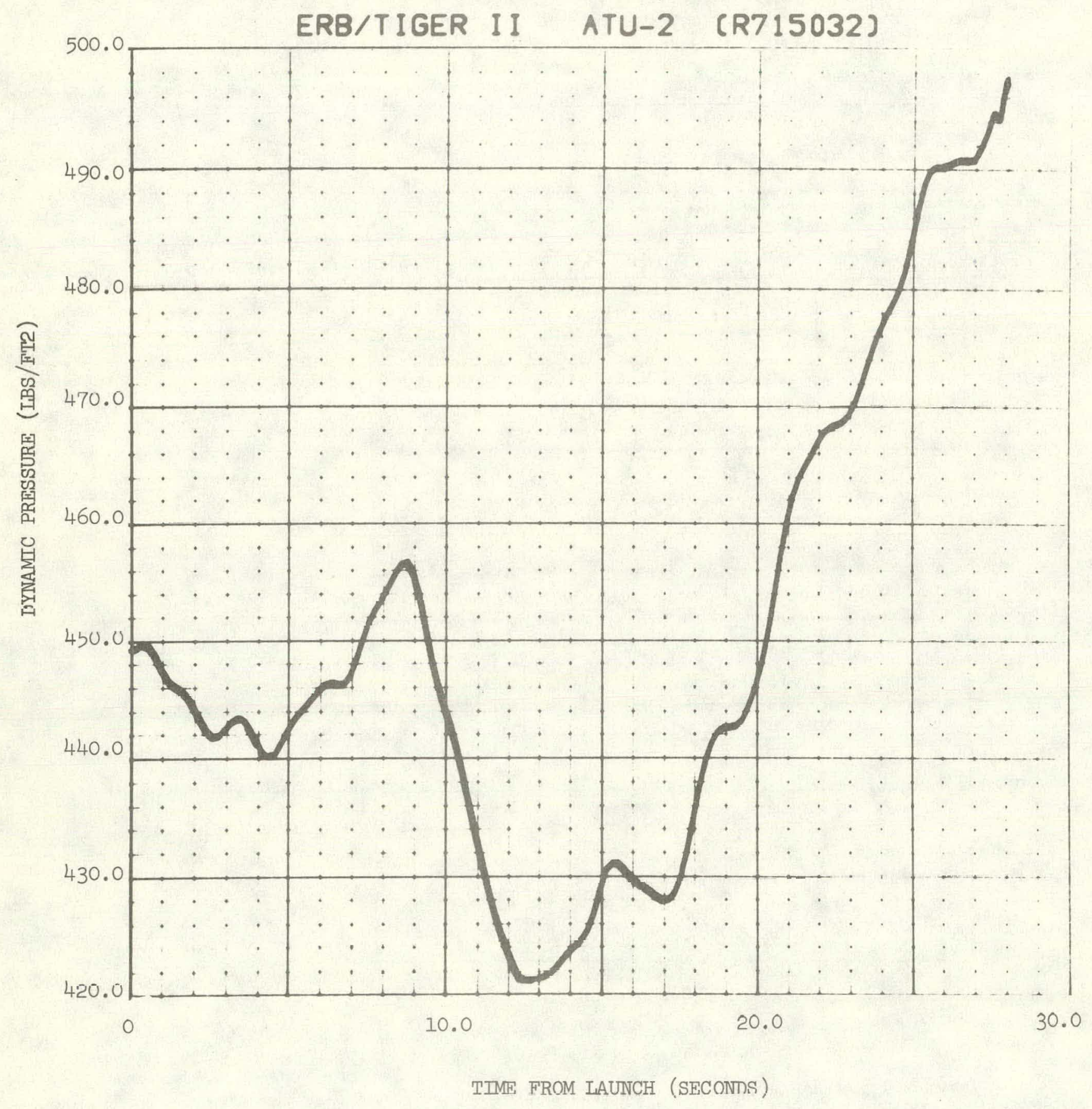

Figure A-10 Dynamic Pressure vs Time From Release 


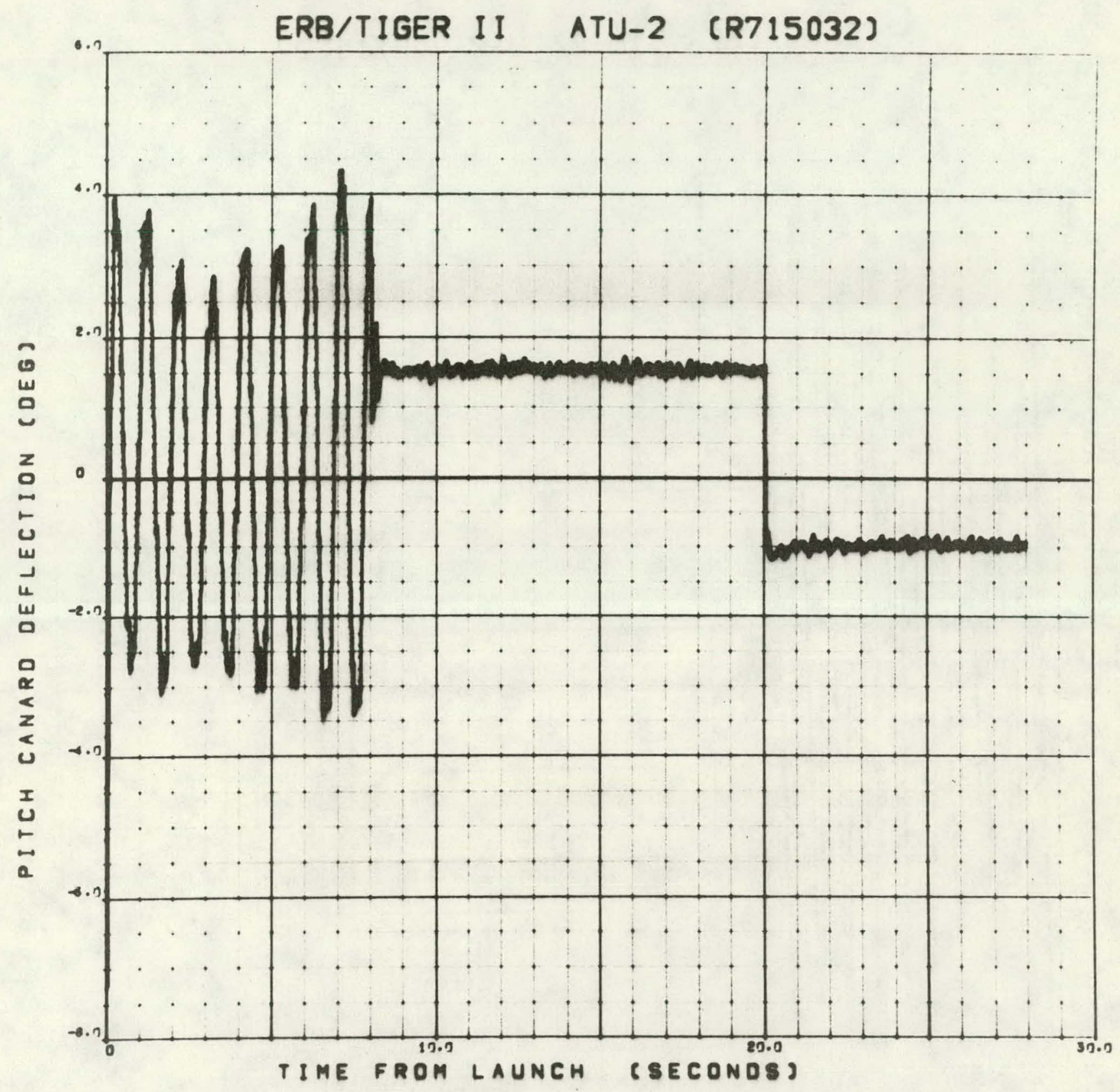

Figure A-11 Pitch Canard Deflection $\left(\delta_{\mathrm{y}}\right)$ vs Time From Release 


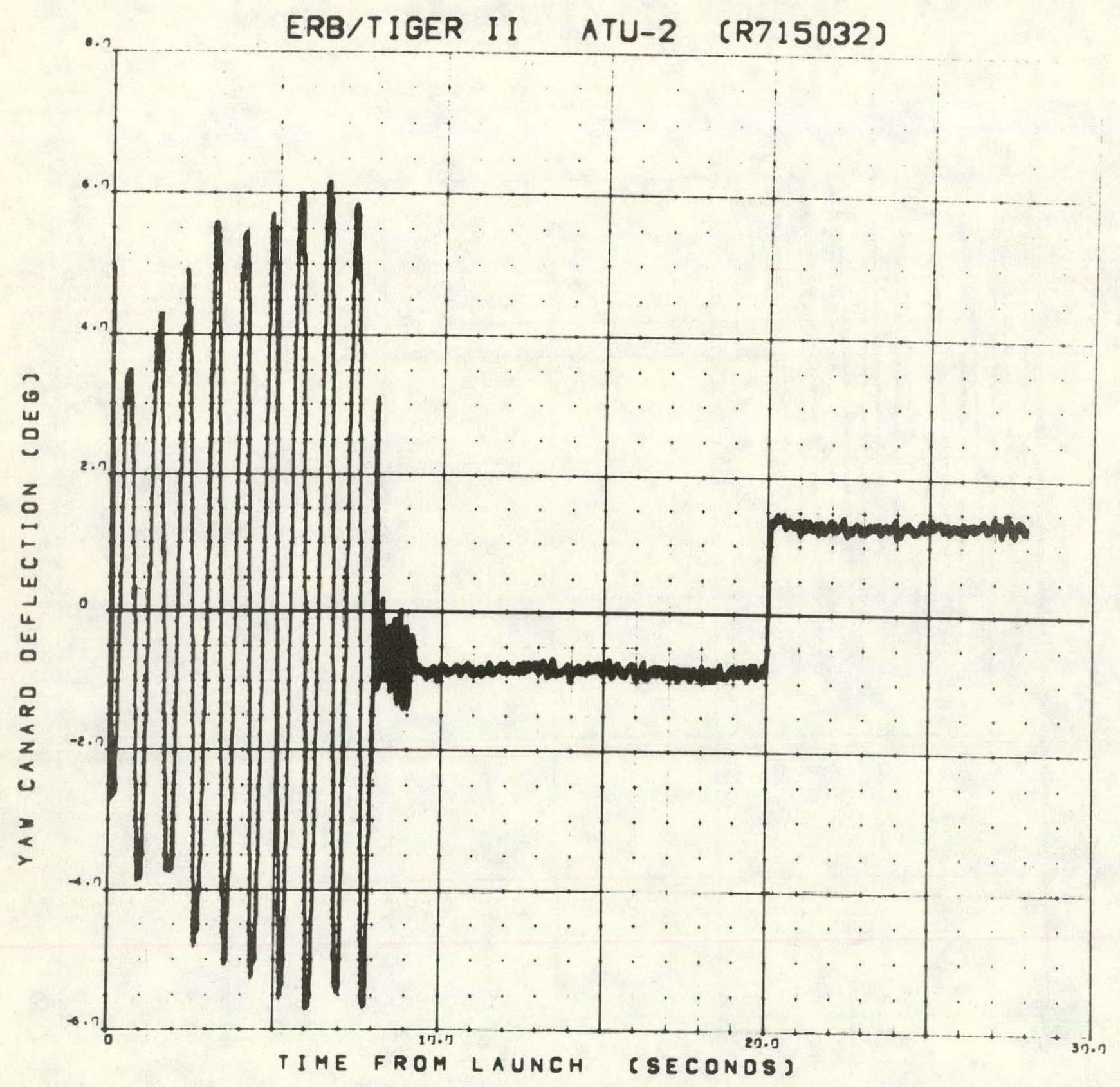

Figure A-12 Yaw Canard Deflection $\left(\delta_{z}\right)$ vs Time From Release 


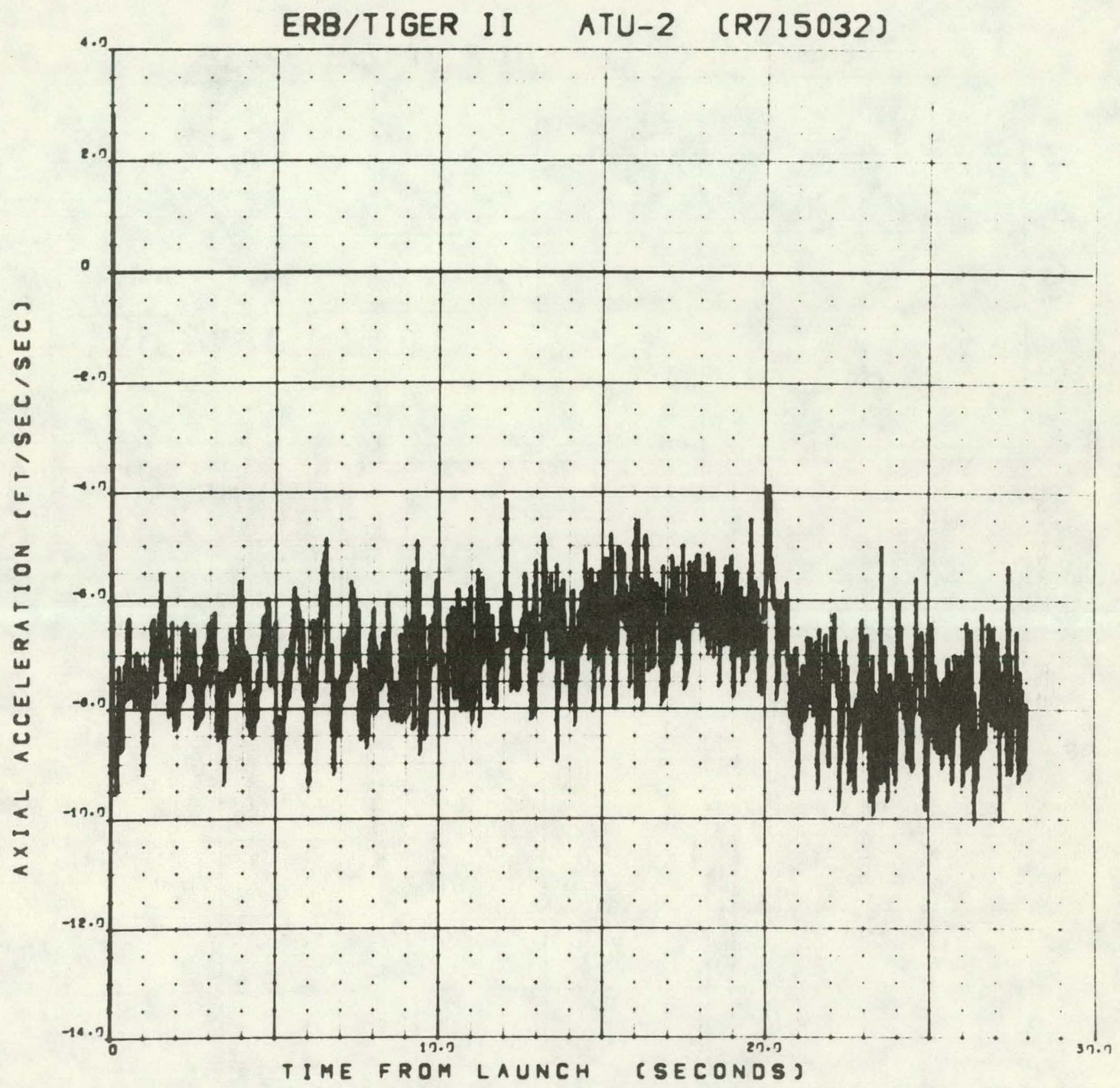

Figure A-13 Body X-Axis Acceleration vs Time From Release 


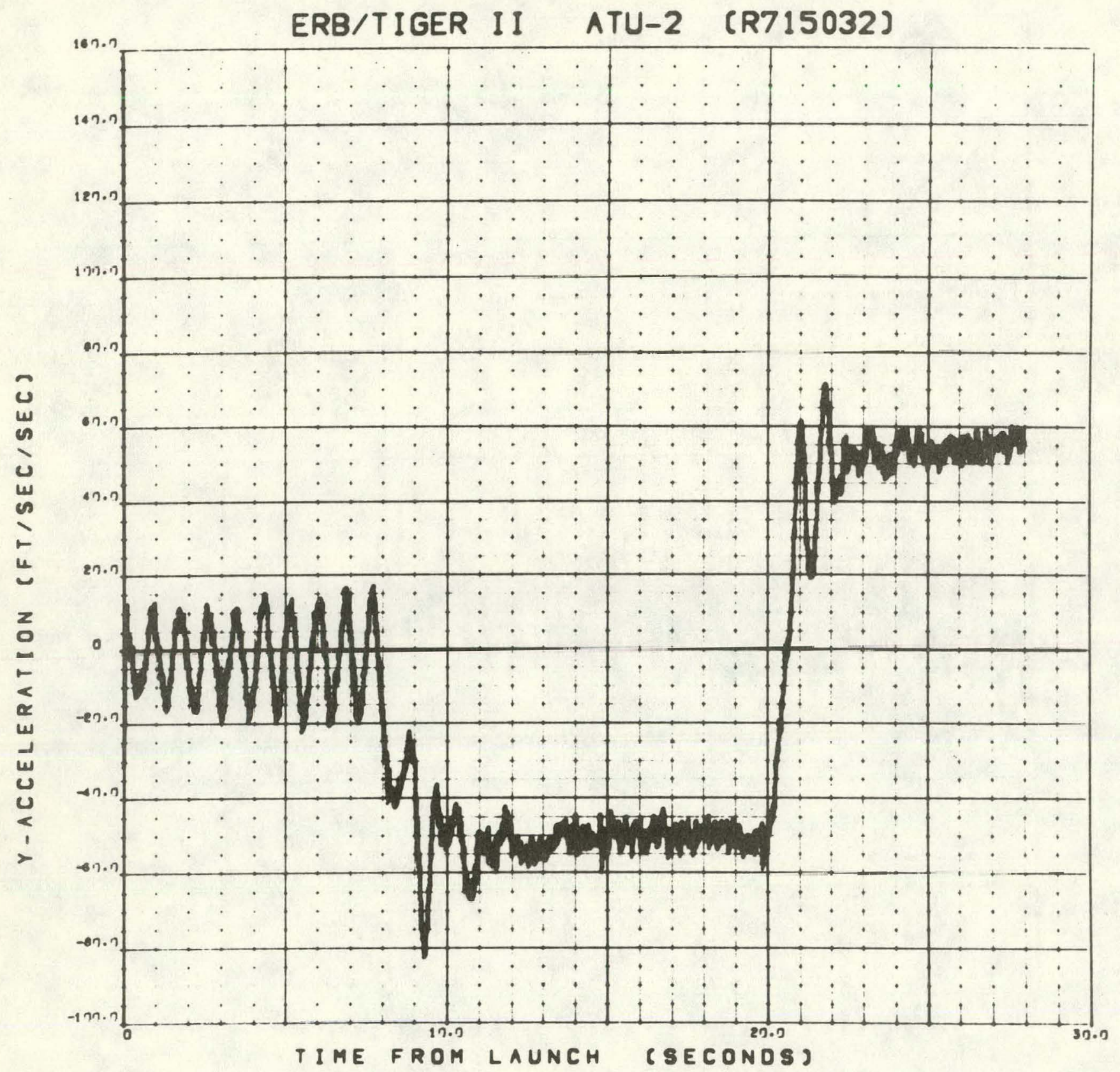

Figure A-14 Body Y-Axis Acceleration vs Time From Release 


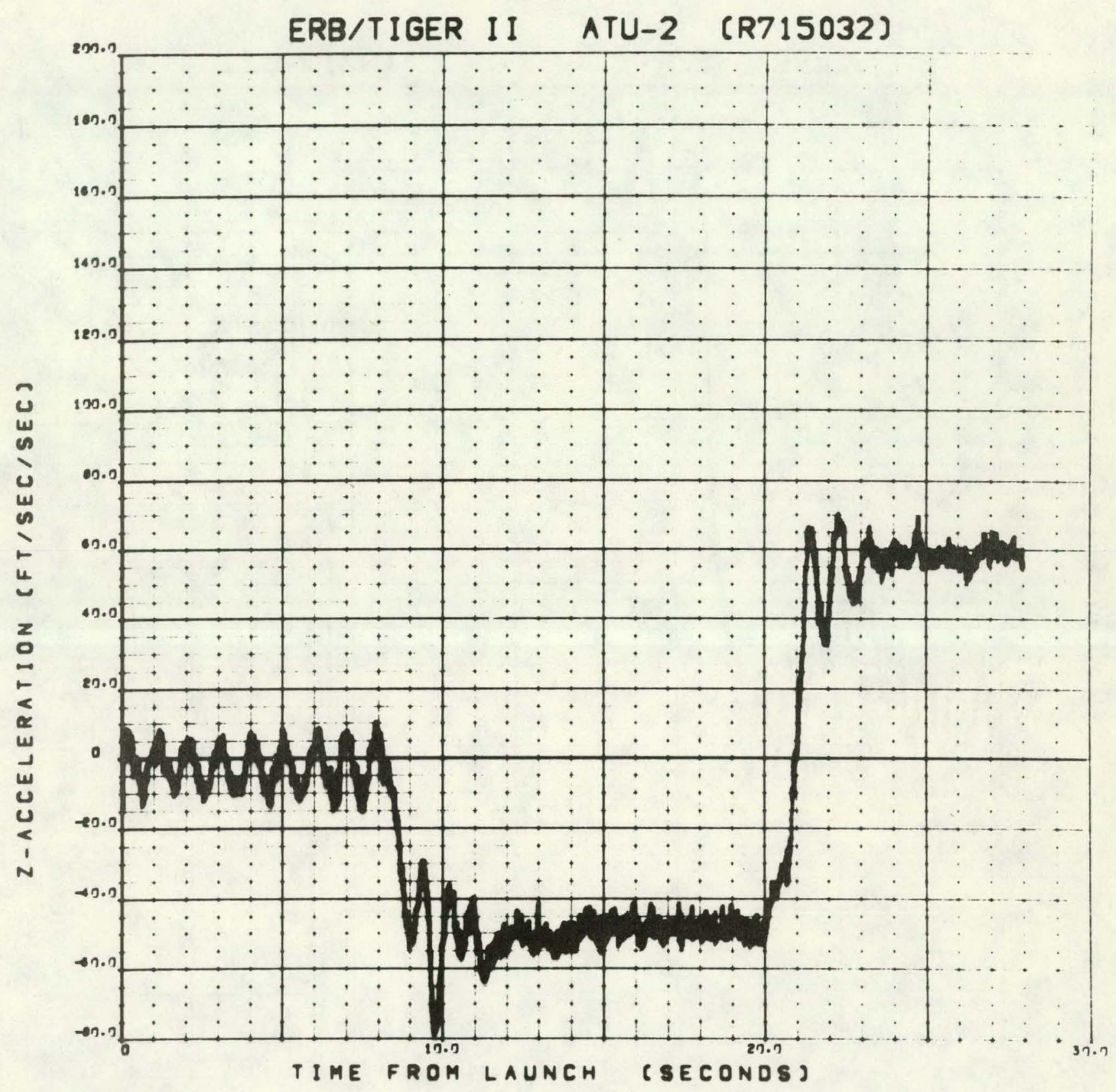

Figure A-15 Body Z-Axis Acceleration vs Time From Release 


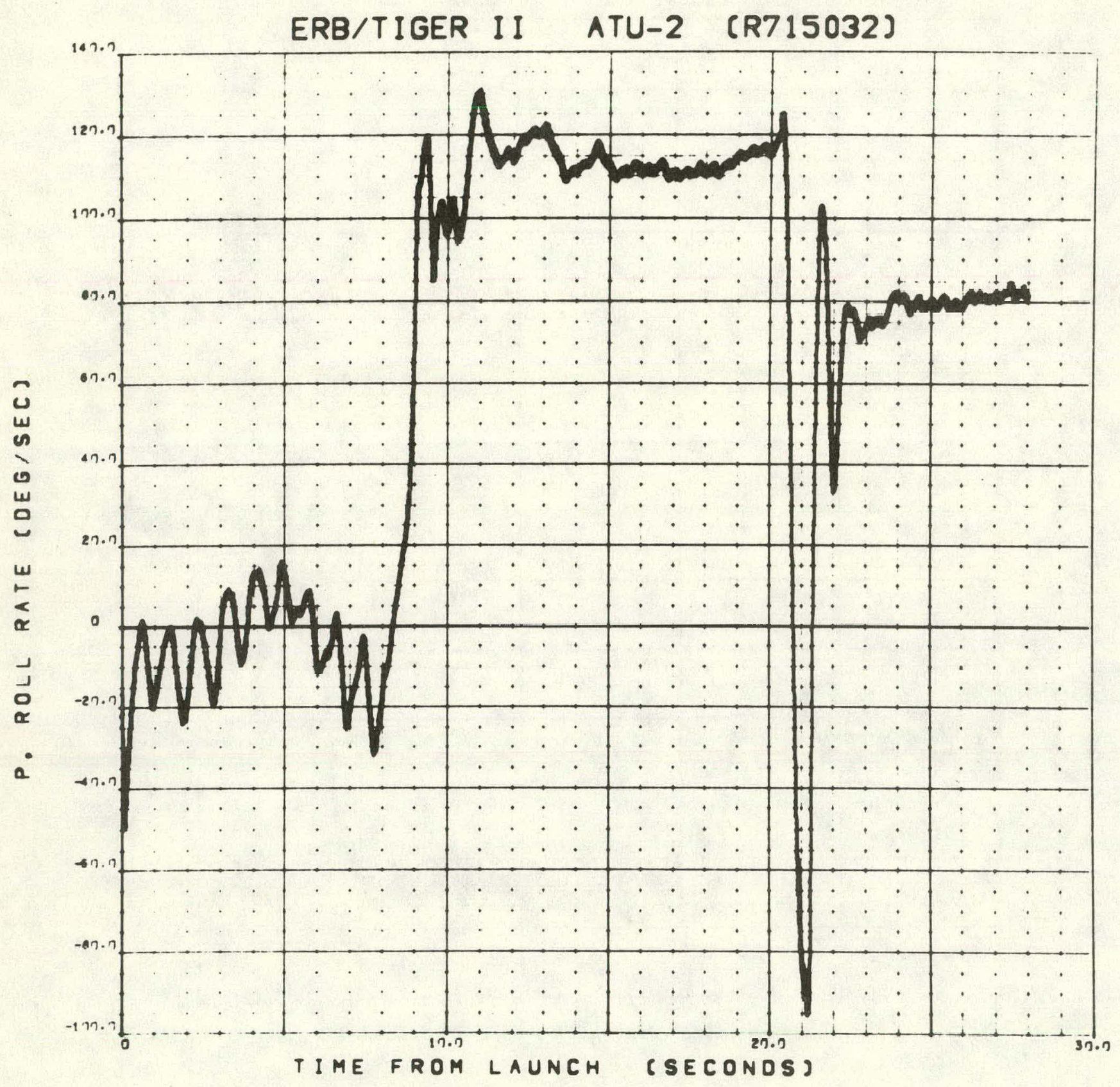

Figure A-16 Body Roll-Rate vs Time From Release 


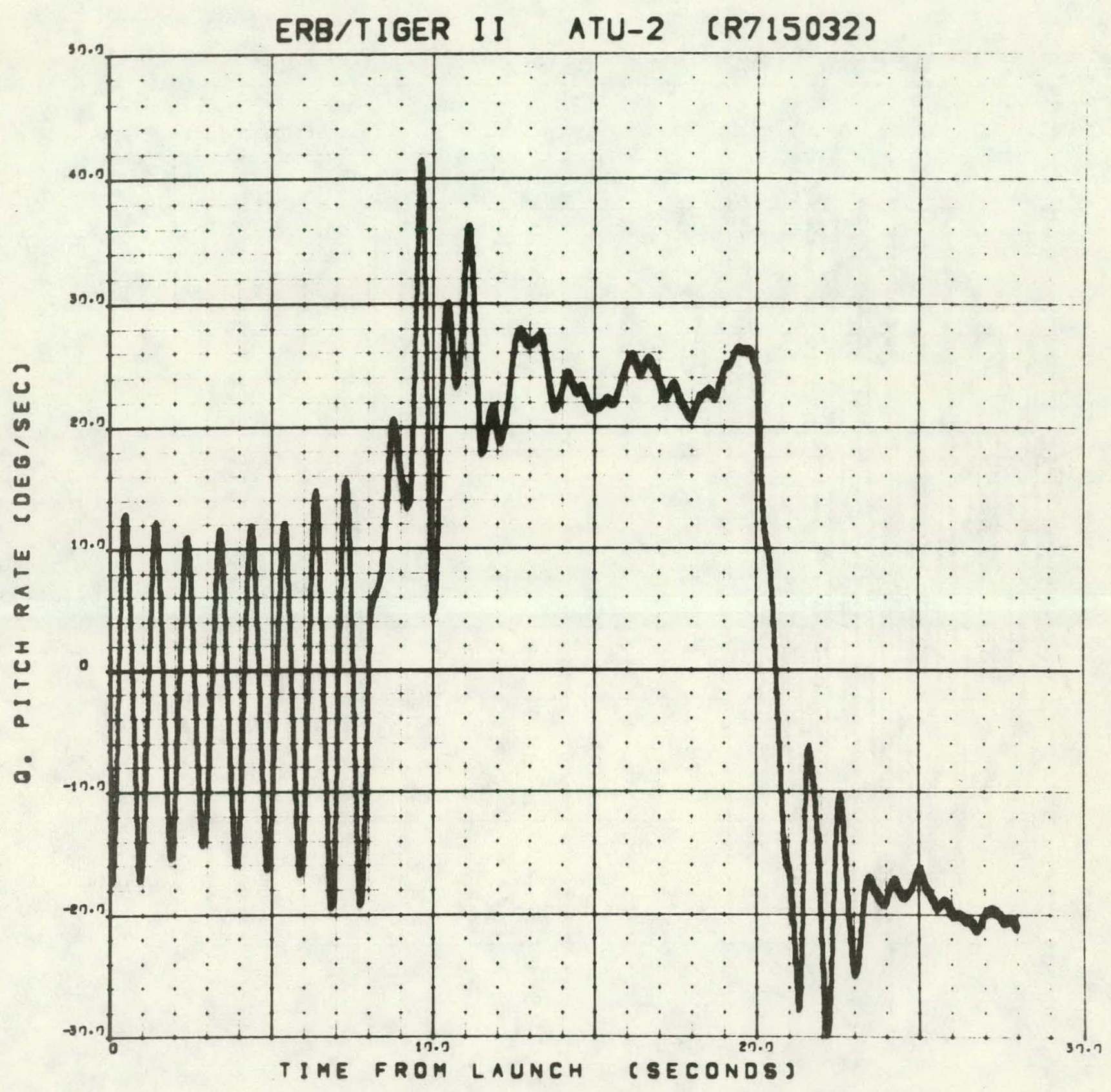

Figure A-17 Body Pitch-Rate vs Time From Release 




Figure A-18 Body Yaw-Rate vs Time From Release

64 


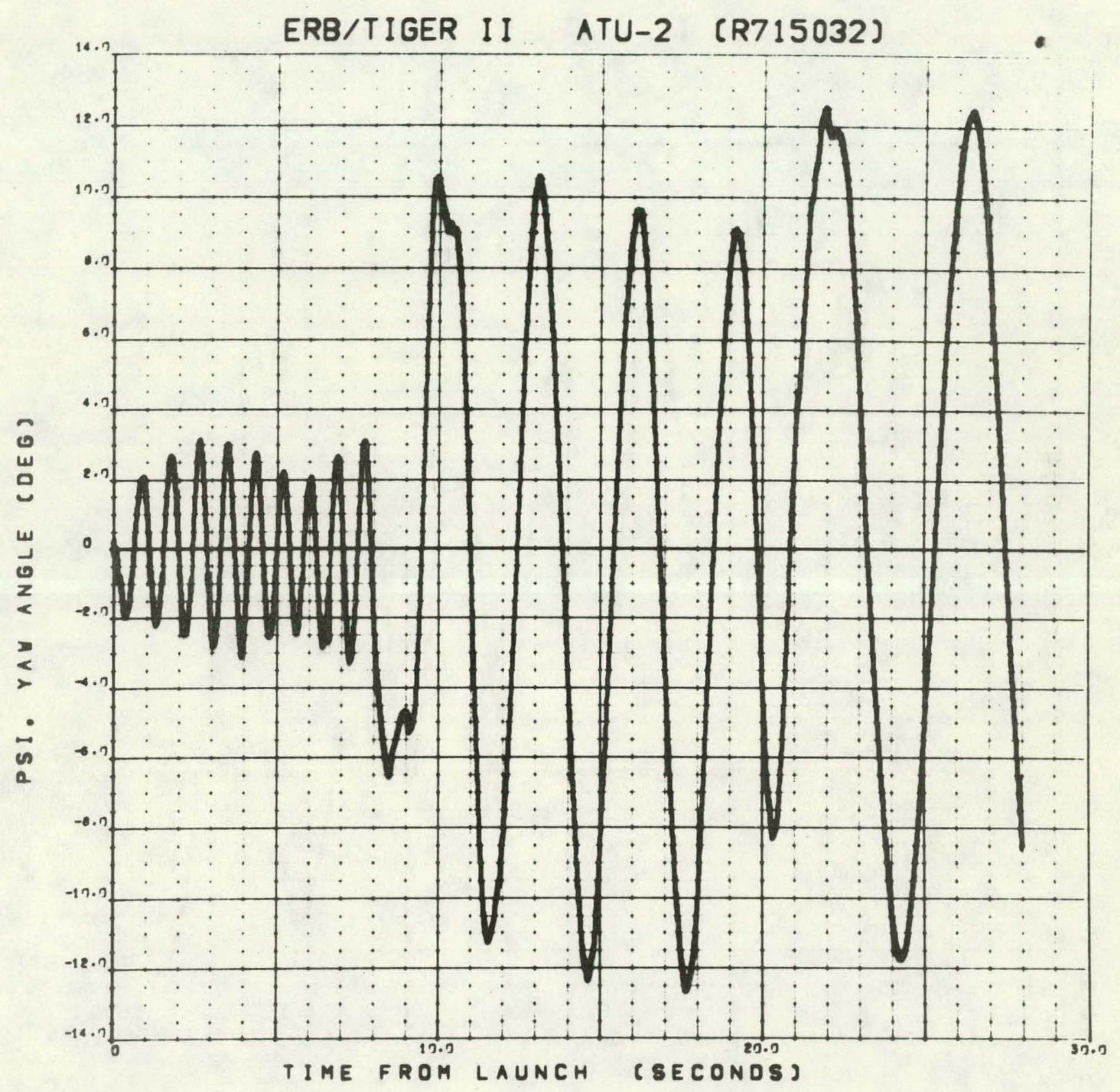

Figure A-19 MARS Yaw Angle vs Time From Release 


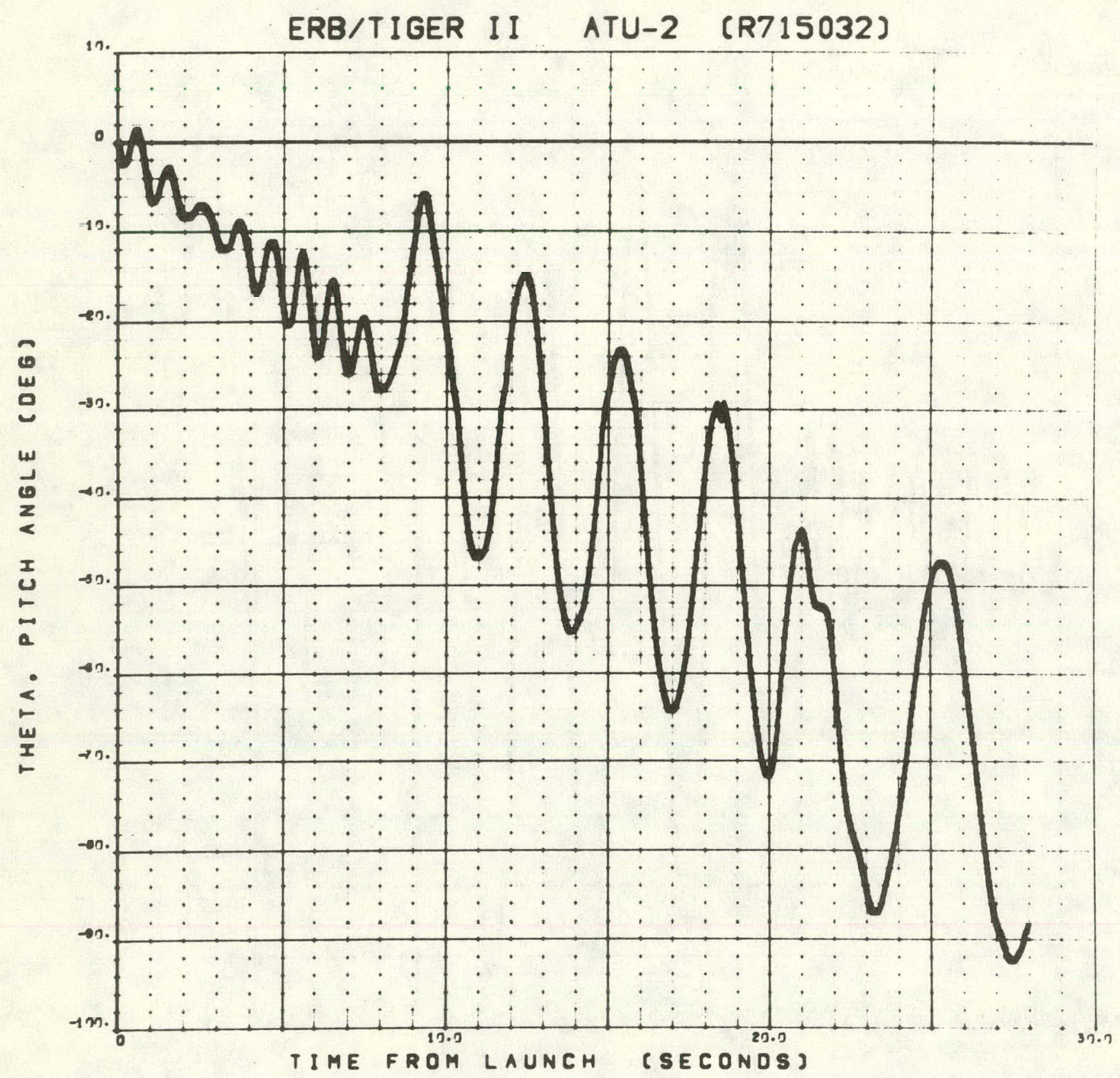

Figure A-20 MARS Pitch Angle vs Time From Release 


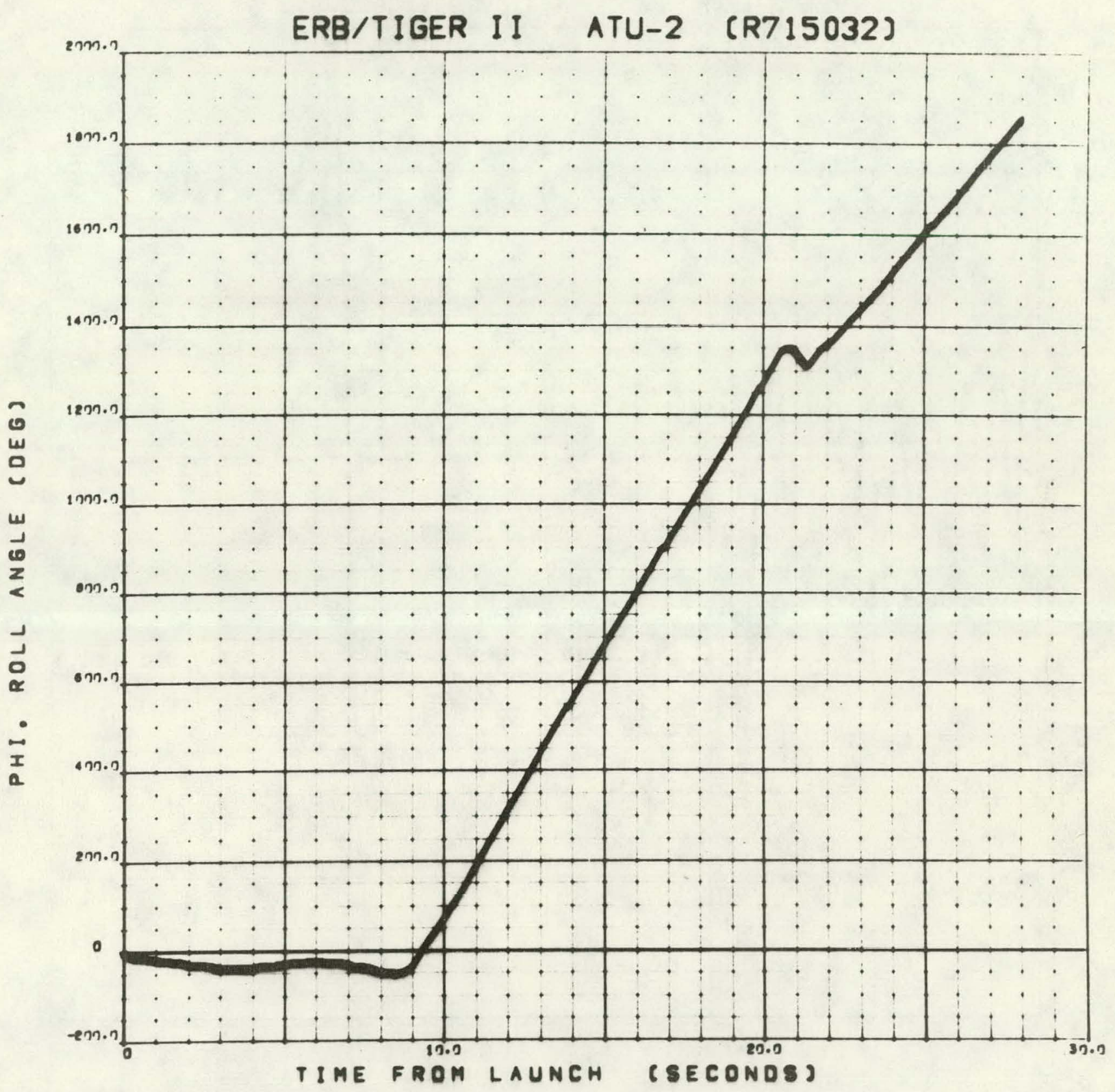

Figure A-21 MARS Roll Angle vs Time From Release 


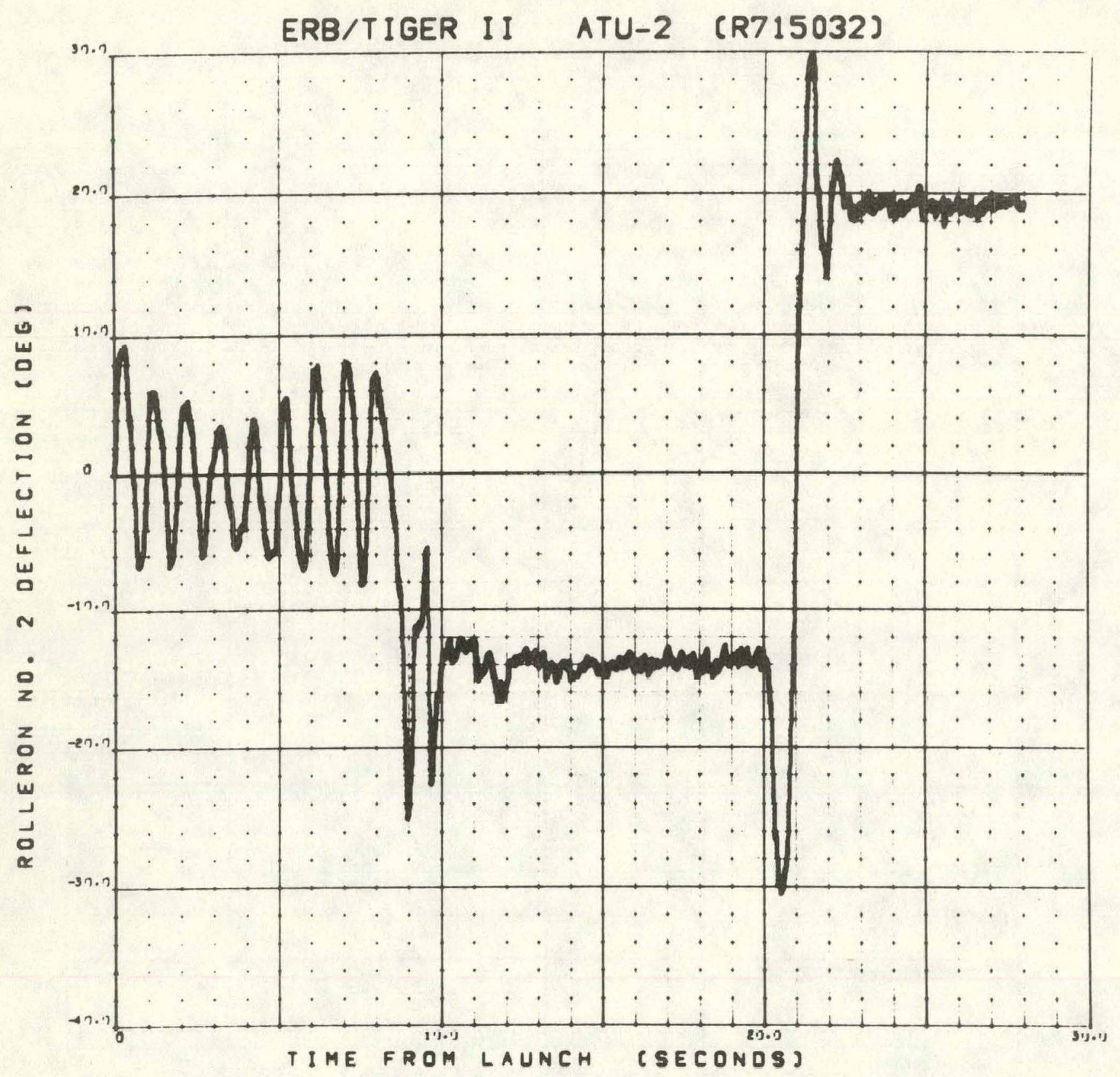

Figure A-22 Deflection of Rolleron 2 vs Time From Release 


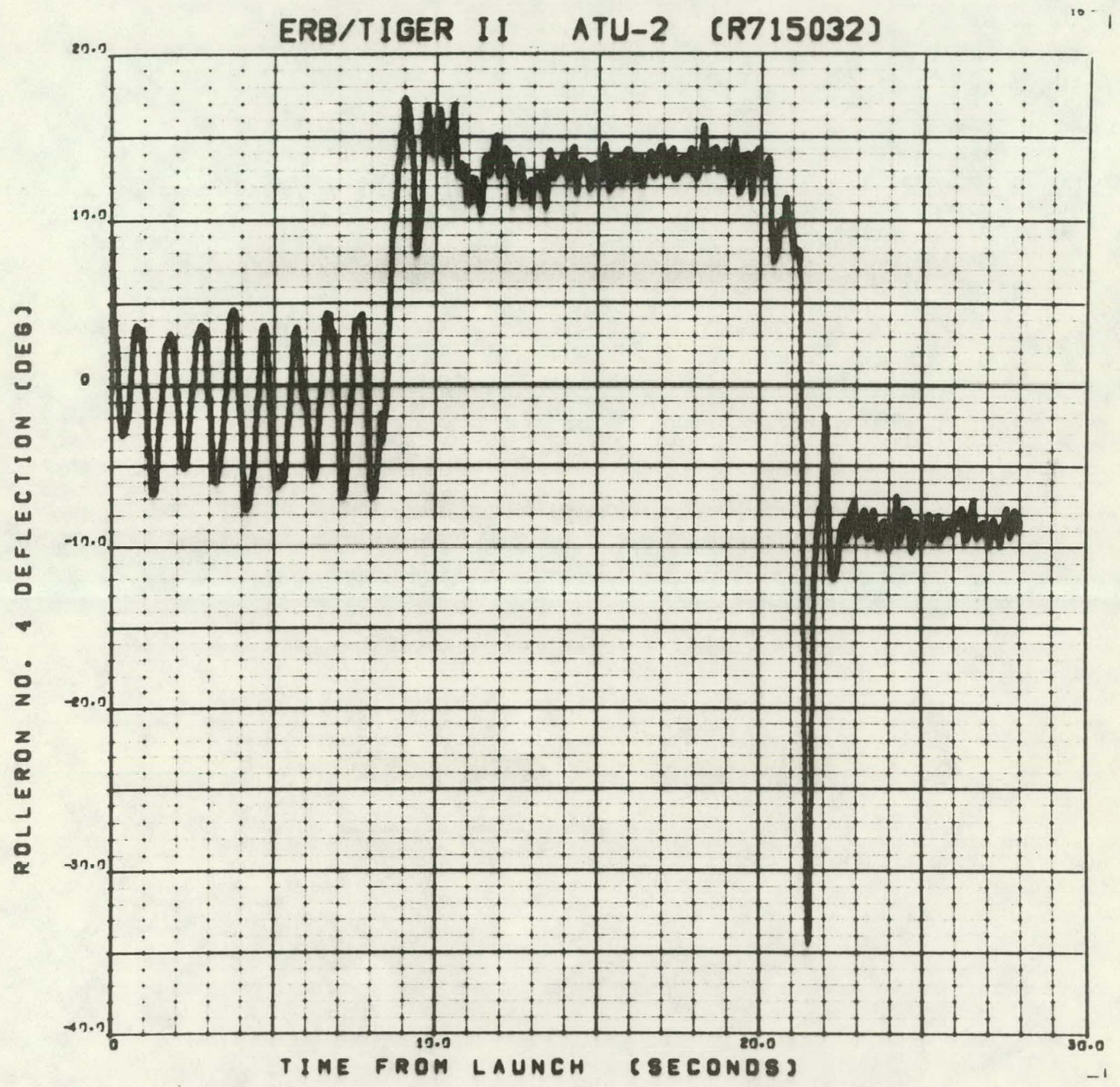

Figure A-23 Deflection of Rolleron 4 vs Time From Release 
DISTRIBUTION :

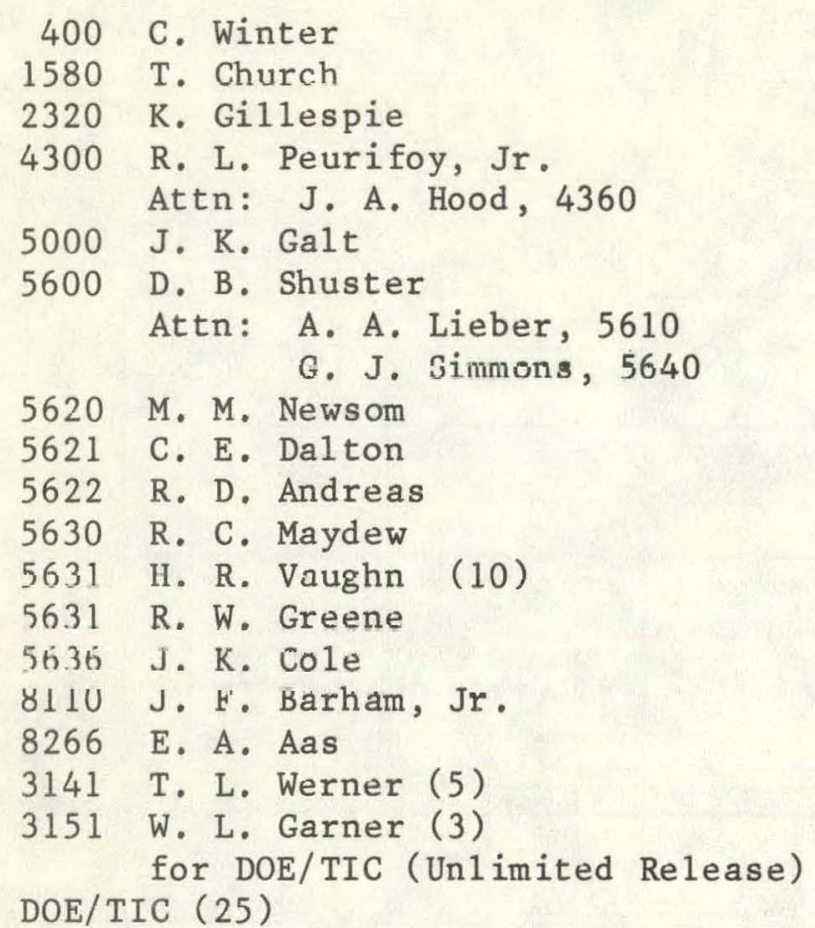

(R. P. Campbe11, 3154-3) 
